Article

\title{
An Investigation of the Quantitative Correlation between Urban Spatial Morphology Indicators and Block Wind Environment
}

\author{
Di Wei ${ }^{\dagger}$, Xing $\mathrm{Hu}^{\dagger}$, Yangjun Chen ${ }^{(0)}$, Baofeng Li and Hong Chen * \\ School of Architecture and Urban Planning, Huazhong University of Science and Technology, Wuhan 430074, \\ China; d202081113@hust.edu.cn (D.W.); d201880899@hust.edu.cn (X.H.); jerryc1112@foxmail.com (Y.C.); \\ libaofeng_1956@hust.edu.cn (B.L.) \\ * Correspondence: chhwh@hust.edu.cn \\ + Both authors contributed equally to this work.
}

Citation: Wei, D.; Hu, X.; Chen, Y.; Li, B.; Chen, H. An Investigation of the Quantitative Correlation between Urban Spatial Morphology Indicators and Block Wind Environment.

Atmosphere 2021, 12, 234. https:// doi.org/10.3390/atmos12020234

Academic Editor: Luca Mortarini Received: 23 November 2020 Accepted: 4 February 2021 Published: 8 February 2021

Publisher's Note: MDPI stays neutral with regard to jurisdictional claims in published maps and institutional affiliations.

Copyright: (c) 2021 by the authors. Licensee MDPI, Basel, Switzerland. This article is an open access article distributed under the terms and conditions of the Creative Commons Attribution (CC BY) license (https:/ / creativecommons.org/licenses/by/ $4.0 /)$.

\begin{abstract}
The research purpose of this work is guiding the spatial morphological design of blocks via relevant indicators to realize suitable wind environments. In doing so, it is necessary to find the most suitable indicator types and value ranges for each urban spatial morphology. At present, most of the relevant research has been based on the numerical simulation of ideal block shapes and rarely proposes results based on actual block types, which often tend to be complex environments. Therefore, this paper firstly presents a theoretical speculation on the main factors influencing indicator effectiveness via analyzing physical significance and formulating principles for each indicator. These speculations are verified via wind environment measurement and statistical analysis, indicating that porosity $\left(\mathrm{P}_{0}\right)$ can be used as an important indicator to guide the design of block wind environments in the case of deep street canyons, while frontal area density $\left(\lambda_{F}\right)$ can be used as a supplement in shallow street canyons with no height differences. Finally, computational fluid dynamics (CFD) is used to quantify the impact of block height difference and street canyon depth on $\lambda_{F}$ and $P_{0}$, thereby finding suitable types of urban form and value ranges for $\lambda_{F}$ and $P_{0}$. This paper provides a feasible wind environment index system for urban designers.
\end{abstract}

Keywords: urban spatial morphology indicator; urban microclimate; computational fluid dynamics; block ventilation; correlation analysis

\section{Introduction}

Urban microclimates are affected by many factors, meaning that they represent an interdisciplinary field; however, the perspectives and contributions of different disciplines are often different. In terms of architecture and urban planning, one of the main research objectives is to find the describable laws between urban morphologies and urban microclimates in order to optimize urban microclimates through effective urban spatial morphology control. Therefore, the parameter pertaining to the urban spatial morphology is an important correlation factor between the urban form and urban microclimate. Through the relevant indicators, it could guide the spatial morphological design of blocks to realize suitable wind environments. Japanese meteorologist Lettau used the concept of "roughness" in 1969 to calculate the impact of underlying urban surfaces on wind environments. Many urban spatial morphology indicators for studying various elements of urban microclimates have been proposed. These indicators can be divided into two categories: One is the "original indicators" of urban planning and architecture, such as the building density, floor area ratio, line sticking rate, etc. Another includes "derived indicators" that have been introduced and developed from meteorology and aerodynamics, among others, such as rugosity, porosity, sky-view factor, etc.

In terms of the research on the correlation between urban morphologies and urban microclimates, urban spatial morphologies can be expressed through multiple dimensions. Some indicators are comprehensive and detailed, while others choose to only express key 
dimensions. By searching important databases around the world, 48 urban spatial morphology indicators (including 15 native indicators and 33 derived indicators) are considered here. These indicators have been divided into three categories according to their different dimensions, including (1) one-dimensional indicators, which only represent the morphological characteristics of urban canopies in the vertical direction, (2) two-dimensional indicators, representing the morphological characteristics of urban canopies on the plane or elevation (windward), (3) and three-dimensional indicators, which comprehensively represent the spatial volume characteristics of urban canopies. The indicators of each category are sorted according to their sequence of occurrence (Table 1).

Table 1. Urban spatial morphology indicators table.

\begin{tabular}{|c|c|c|c|}
\hline \multicolumn{4}{|c|}{ One-Dimensional Indicators } \\
\hline 1 & $Z_{\mathrm{o}}$ & aerodynamic roughness length [1] & 1969, Lettau H \\
\hline 2 & $Z_{\mathrm{r}}$ & blending height [2] & 1970, Pasquill \\
\hline 3 & $\mathrm{Z}_{\mathrm{d}}$ & zero-plane displacement height [3] & 1982, Shaw and Pereira \\
\hline 4 & $\mathrm{~h}$ & roughness [4] & 1986, Kondo J, Yamazawa H \\
\hline 5 & $\sigma_{\mathrm{H}}$ & standard deviation of building heights [5] & 1997, Rafailidis \\
\hline 6 & $\bar{H}$ & average building height [6] & 1999, Ratti C \\
\hline 7 & $\overline{H^{2}}$ & average of building heights squared [6] & 1999, Ratti C \\
\hline 8 & $\mathrm{Z}_{\mathrm{H}}$ & average building height (frontal area) [6] & 1999, Ratti C \\
\hline 9 & $\mathrm{H}_{\mathrm{m}}$ & absolute rugosity $[7,8]$ & 2001, Adolphe L \\
\hline 10 & $\Delta \mathrm{H}$ & expandability [9] & 2015, Zhang \\
\hline \multicolumn{4}{|c|}{ Two-dimensional indicators } \\
\hline 11 & $\mathrm{~g}_{\mathrm{aM}}$ & surface conductance $[10]$ & 1986, Hicks and Hosker \\
\hline 12 & $\mathrm{H} / \mathrm{W}$ & aspect ratio [11] & 1988, Oke T \\
\hline 13 & $\mathrm{~L} / \mathrm{W}$ & aspect ratio [11] & 1988, Oke T \\
\hline 14 & $\lambda_{\mathrm{P}}$ & plan area density [12] & 1993, Theurer \\
\hline 15 & $\lambda_{\mathrm{F}}$ & frontal area density [12] & 1993, Theurer \\
\hline 16 & $\lambda_{\mathrm{p}} \lambda_{\mathrm{f}}$ & packing densities [13] & 2010, Santiago and Martilli \\
\hline 17 & $\lambda_{\mathrm{f}(\Delta \mathrm{z})}$ & frontal area density [14] & 2011, Edward \\
\hline 18 & $\mathrm{~N}_{1}$ & street network linear density [15] & 2011, Yuan \\
\hline 19 & $\mathrm{~N}_{\mathrm{a}}$ & street network areal density [15] & 2011, Yuan \\
\hline 20 & $\zeta_{\mathrm{s}}^{\mathrm{a}}$ & windward area ratio [16] & 2013, MOHURD \\
\hline 21 & $\overline{\zeta \mathrm{s}}$ & mean windward area ratio [16] & 2013, MOHURD \\
\hline 22 & $\zeta_{\mathrm{v}}$ & volumetric blocking ratio [16] & 2013, MOHURD \\
\hline 23 & $\zeta$ & ventilation obstruction ratio [16] & 2013, MOHURD \\
\hline 24 & $\mathrm{k}$ & ventilation overhead rate [16] & 2013, MOHURD \\
\hline 25 & $\mathrm{C}$ & surround ratio [9] & 2015, Zhang \\
\hline 26 & $\mathrm{~N}$ & stick line ratio [17] & 2016, Zhou \\
\hline 27 & $\mathrm{~L} / \mathrm{C}$ & plane permeability [18] & 2016, Zhang \\
\hline 28 & - & $\mathrm{BCR}$, ground coverage ratio & - \\
\hline \multicolumn{4}{|c|}{ Three-dimensional indicators } \\
\hline 29 & $\Psi_{\mathrm{S}(\mathrm{H} / \mathrm{W})}$ & SV, sky-view factor [19] & 1973, Oke T \\
\hline 30 & $\Psi_{\mathrm{S} \text { (photo) }}$ & SV, sky-view factor [20] & 1980, Steyn D \\
\hline 31 & - & fractality $[7,8]$ & 1994, Frakhause P \\
\hline 32 & - & confinement $[7,8]$ & 1997, Dupagne A, etc \\
\hline 33 & $\lambda_{c}$ & complete aspect ratio [21] & 1997, Voogt J, Oke T \\
\hline 34 & - & regularity $[7,8]$ & 1998, Maïzia M \\
\hline 35 & $\mathrm{R}_{\alpha}$ & relative rugosity $[7,8]$ & 2001, Adolphe L \\
\hline 36 & $\mathrm{P}_{0}$ & porosity $[7,8]$ & 2001, Adolphe L \\
\hline 37 & $\mathrm{~S}_{\theta}$ & sinuosity $[7,8]$ & 2001, Adolphe L \\
\hline 38 & $\mathrm{O}_{\mathrm{c}}$ & occlusivity $[7,8]$ & 2001, Adolphe L \\
\hline 39 & $\mathrm{G}_{1}$ & compacity $[7,8]$ & 2001, Adolphe L \\
\hline 40 & $\mathrm{Ct}$ & contiguity $[7,8]$ & 2001, Adolphe L \\
\hline 41 & M & mineralization $[7,8]$ & 2001, Adolphe L \\
\hline 42 & $\Psi_{\mathrm{S} \text { (face) }}$ & SVF, sky-view factor $[22,23]$ & 2005b, Kanda M, etc \\
\hline 43 & $\mathrm{P}_{\mathrm{b}(\mathrm{z})}$ & floor density distribution [24] & 2005, Kondo H \\
\hline 44 & $\mathrm{~m}$ & volume porosity [24] & 2005, Kondo H \\
\hline 45 & V & envelope ratio [25] & 2006, Shashua-Bar, etc. \\
\hline 46 & $\mathrm{P}_{\mathrm{oc}}$ & comprehensive porosity [26] & 2012, Xin \\
\hline 47 & $\Psi_{\mathrm{S} \text { (sectors) }}$ & SVF sectors [27] & 2018, Zhang \\
\hline 48 & - & Floor Area Ratio (FAR) & - \\
\hline
\end{tabular}

Due to the different theoretical starting points and limitations of respective disciplines, the two kinds of indicators detailed here have their own advantages and disadvantages in terms of research and application. The original indicators of architecture and urban planning can be more easily connected with design methods, policies and regulations; however, their response to microclimate change is not sensitive enough, and the effects of guiding climate adaptation urban design are still questionable. On the other hand, derived indicators can often better describe the thermal and dynamical characteristics of urban canopies; however, according to the existing research results, there is no derived indicator 
that can effectively solve all the entailing problems. Regarding block wind environment representations, different indicators have different block shape types and special value ranges for which they are most applicable. Therefore, it is not possible to draw a general conclusion for the research purpose of guiding the wind environment design of blocks by controlling indicators, and the most appropriate indicators should be found according to different situations.

Under this background, the existing research usually adopts a numerical simulation research method. This means to (1) carry out classified discussion for different types of blocks and set different series of working conditions by changing the spatial morphologies of blocks. Next, (2) the statistics for the numerical changes of urban spatial morphology indicators are evaluated, as well as the changes in terms of the wind environments within blocks. Finally, (3) a correlation model for the numerical change of the two datasets is constructed in order to analyze and compare the applicability of each indicator under different circumstances and elucidate the most applicable block shape types and value ranges for each indicator.

The biggest challenges with this approach are the following: In order to realize the effective representation of all block spatial morphology changes, it is necessary to combine qualitative descriptions with quantitative parameterized descriptions. The variables involved in this include the differences between block types (such as their geographical environment, urban location, construction intensity, and architectural form), and, under each type, the parameter changes of block morphology in each dimension (such as horizontal, vertical, and windward). The large number of working conditions formed by the various permutations and combinations of these variables leads to difficulties in research. Therefore, most of the existing research results are based on specific block types (such as slab residential communities) with an ideal block morphology (i.e., all buildings have the same height, plane, and spacing).

Considering the limitation of the current computing power of computers, while an effective method for block space classification has not been proposed yet, this paper adopts a new idea. While most derivative indicators are calculated by thermodynamic and kinetic formulae with physical meaning, this paper attempts to clarify their physical meanings and formulate principles, and analyze their congenital defects when applied to the study of block wind environments. This is carried out to produce theoretical speculations regarding the main factors affecting the effectiveness of each indicator and to reduce huge investigation workload. On this basis, eight residential districts (including 19 measuring points in total) in Wuhan, China, are selected for on-site wind environment measurement in order to verify the previous theoretical predictions. Numerical simulation with computational fluid dynamics (CFD) is used to quantify the applicability of each indicator.

\section{Review}

When the derived indicators from other disciplines are introduced and used to represent urban spatial morphologies, many parameters in the calculation formula typically cannot be directly obtained from a real city, meaning that a hypothetical city model needs to be established as a transformation medium. However, once the scale of the model reaches the city-block-scale or beyond, there are inevitable challenges. For example, how can we give consideration to the complexity and diversity of the simulated objects (i.e., real urban spatial morphologies) while maintaining the simplicity and readability of the model?

To solve this problem, a hypothetical city model based on the derived indicators can be divided into two categories in terms of the solution perspectives. One perspective is to establish a geometrical model, thereby simplifying the real city with a uniform and regular arrangement of cubes. In related research, these models are expressed as "simple averaged building models" or "canyon models". Another perspective is to build a topology model and homogenize small differences by "reducing the resolution". In this way, the basic texture of the real city can be retained while the expression difficulty is reduced. 
According to the literature, it was found that most of the derived indicators are closely related to each other from a theoretical perspective. Therefore, although these indicators have been proposed by scholars with different backgrounds and span more than half a century, they are still feasible for discussion together (Figure 1). Combining the current research hotspot of block morphologies and block ventilation, six derived indicators of urban spatial morphologies are considered here, including the sky-view factor $\left(\Psi_{\mathrm{s}}\right)$, plan area density $\left(\lambda_{\mathrm{P}}\right)$, frontal area density $\left(\lambda_{\mathrm{F}}\right)$, porosity $\left(\mathrm{P}_{0}\right)$, rugosity $\left(\mathrm{R}_{\alpha}\right)$, and sinuosity $\left(\mathrm{S}_{\theta}\right)[28]$.

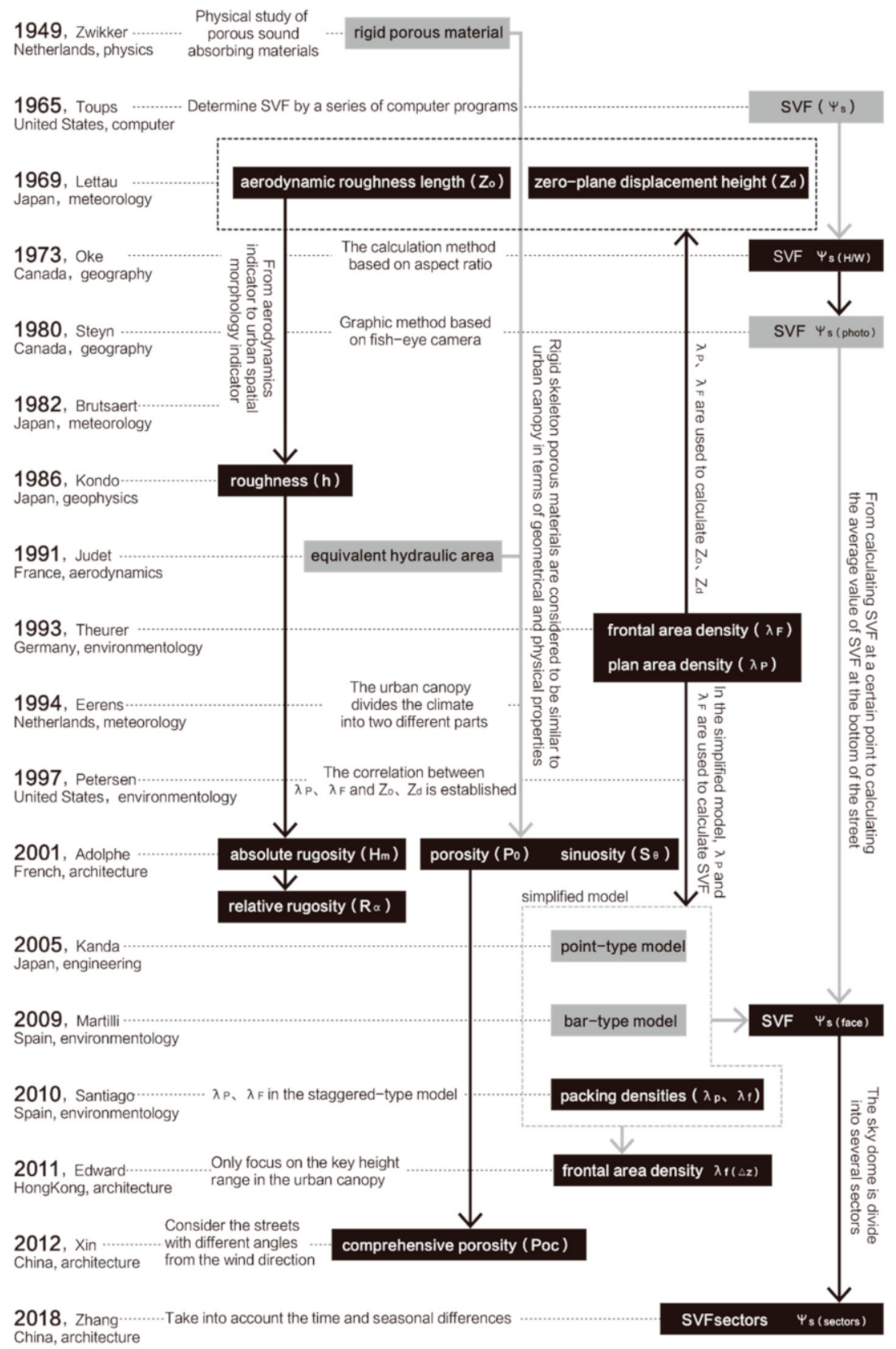

Figure 1. Relationships between the derived indicators.

\subsection{The Theory of Geometrical City Models}

With the intrinsic unrepeatability of real urban morphologies, conclusions based on field measurements often come with limitations. To find general conclusions and reduce the amount of calculation at the same time, simple building-averaged models have been proposed. These models arrange all buildings in a regular order, where the buildings have 
the same sizes and spacings. One of the most important examples is the "canyon model" proposed by Oke in the 1970s, which considers a city street bound by two building facades that extend indefinitely. Based on this street canyon geometry, various simplified urban models (common examples include point-type, bar-type, and staggered-type models) have been proposed to study radiant heat transfer and street canyon wind environments in cities (Johnson, 1991; Mills, 1993; Arnfield, 1998) [29-31].

In mesoscale (city-block-scale) studies, the theoretical basis of averaged methods is that the evaluation objects should be the overall heat flux, turbulent kinetic energy, and wind field in the urban canopy, and that the independent morphologies and influences of each building should not be taken into account. The research by Spanish environmentalist Martilli partly supports the feasibility of this theory [32]. In this paper, five urban block segments (from London, Berlin, Salt Lake City, Los Angeles, and Toulouse) with huge differences in texture are selected as experimental subjects. The results show that the simplified model is able to reproduce a real city in terms of thermal performance by extracting various morphological parameters in real cities.

Based on the simplified geometric model, many urban spatial morphology indicators have been proposed and applied, including the plan area density $\left(\lambda_{P}\right)$, frontal area density $\left(\lambda_{\mathrm{F}}\right)$, packing densities $\left(\lambda_{\mathrm{p}}, \lambda_{\mathrm{f}}\right)$, and sky-view factor $\left(\Psi_{\mathrm{s}}\right)$.

Relevant works have adopted point, bar, orderly, and staggered models to cross-verify the effectiveness of calculations; however, mainstream simplified geometric models are based on the premise that all buildings are of the same height. Therefore, calculation formulae for this kind of derived indicator cannot reflect random changes in the heights of urban canopies, so it is difficult to accurately reflect the entailing impact on the wind environment. Martilli (2002) [33] pointed out that $\lambda_{F}$ should be used with caution when applied to highly variable blocks.

Conjecture 1: SVF, $\lambda_{\mathrm{P}}$, and $\lambda_{\mathrm{F}}$ may only work if there is little change in height between buildings, and the degree of variation in the vertical direction of an urban canopy may be the main factor that affects the effectiveness with these indicators.

\subsection{The Theory of Topological City Model}

Different from the research concept of simplifying urban morphologies, topological changes in real complex urban spatial morphologies are considered from a completely different perspective. Adolphe $(2001 \mathrm{a}, \mathrm{b})[7,8]$, the most representative researcher, studied how to use simple topological indicators to directly represent real complex urban forms by borrowing from the theory of fluid propagation in porous media.

Adolphe's theory was based on the study of sound absorbing materials by the Dutch physics professors Zwikker (1949) [34]. Zwikker studied five types of sound-absorbing materials: high-elastic impermeable materials, rigid skeleton porous materials, elastic skeleton porous materials (with open surface), elastic skeleton porous materials (with coated surface), and porous materials with an air layer. Among them, the rigid skeleton porous material was creatively referenced by Adolphe due to its geometrical and physical characteristics, which are similar to an urban canopy. In addition, in the physical experiment on the internal airflow of rigid porous materials, Zwikker proposed the indicators of porosity and sinuosity to evaluate the impact of pore volume and shape on airflow, which has great significance for the study of wind environments inside urban canopies. Inspired by this, Adolphe re-described the urban canopy from a three-dimensional perspective, changing its topology into a porous medium with a rigid skeleton. Based on this, a variety of urban spatial morphology indicators have been proposed, including relative rugosity $\left(\mathrm{R}_{\alpha}\right)$, porosity $\left(\mathrm{P}_{0}\right)$, and sinuosity $\left(\mathrm{S}_{\theta}\right)$.

In summary, since these derived indicators are limited to the evaluation of the internal pore airflow in porous media (i.e., street valley wind), this means that the assumption of changing the topology of the urban canopy to a rigid porous medium is based on the distinction between two different wind environments, meaning that wind environments above urban canopies and those within them need to be discussed separately. This is likely 
to limit the scope of application of these indicators. It is not difficult to deduce that the above indicators will be more accurate for deep street canyons and may fail for shallow street canyons. This is because there will be a large and complex air exchange between the upper- and inner-city canopies, and this exchange cannot be discussed separately.

Conjecture 2: $P_{0}, R_{\alpha}$, and $S_{\theta}$ may only be applicable to the conditions relevant to deep street canyons, and the depths of street canyons in blocks (i.e., the ratio of height to width of street canyons, H/W) may be the main factor affecting the effectiveness of these indicators.

\section{Materials and Methods}

\subsection{Wind Environment Data Collection Based on Real Urban Morphology}

\subsubsection{Site Selection}

The above theoretical conjecture was verified by measured data. In the selection of the measured objects, the following principles were followed:

- Within $1 \mathrm{~km}$ of the measuring point, and there is a large area with no occlusion that can be used as a reference point;

- Each measuring point has the same land use (block function), similar surrounding terrain, and population density, so as to reduce the influence of background factors;

- The selected objects should cover as many changes as possible in the block form (architectural layout, density, and height);

- The selected block forms include deep street canyons and shallow street canyons, with both no elevation difference and with obvious elevation difference, which is convenient for further comparative analysis.

Based on this, this paper considered residential areas in Wuhan, China, as research objects. Reference points were selected in Hankou District, Hanyang District, and Wuchang District, respectively. Centers of circular areas were considered for measuring objects within a range of $1 \mathrm{~km}$. A total of 8 residential areas were selected. The types of residential areas included point-type, slab-type, mixed-type, and enclosed-type areas, and the floor area ratio, building density, and building height values were also different (Figure 2a-c).

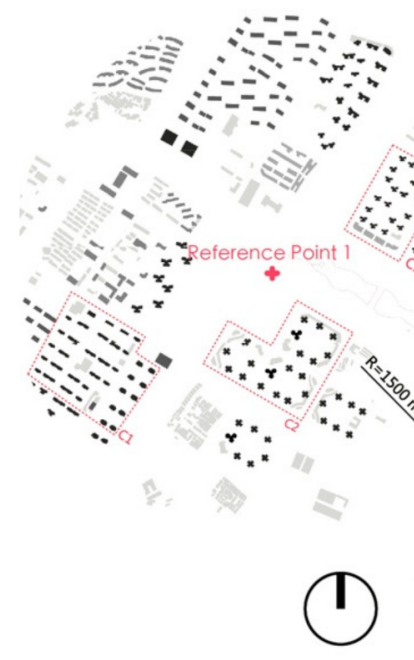

(a)
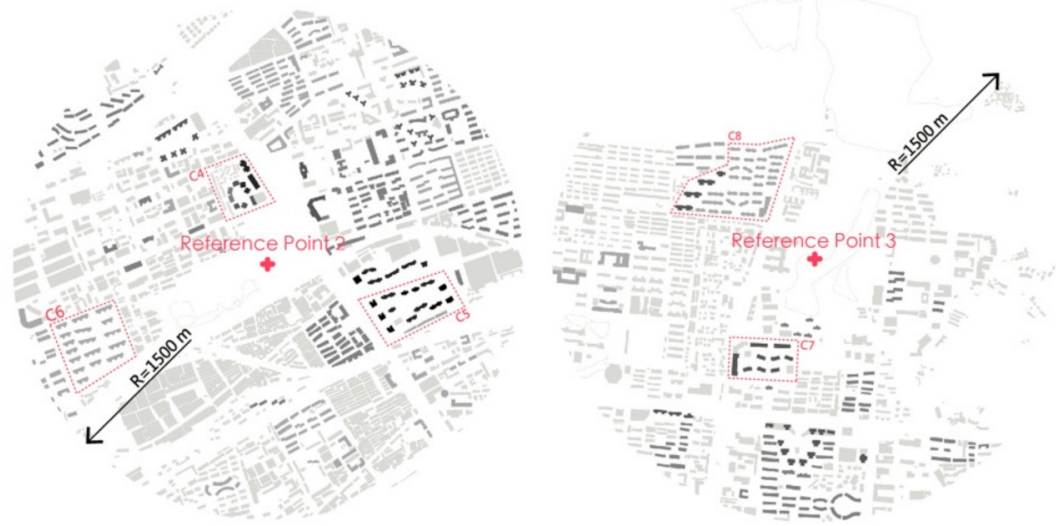

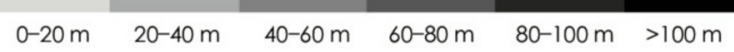

(b) (c)

Figure 2. The selection area for measurement in Wuhan: (a) Hanyang District; (b) Hankou District; (c) Wuchang District.

\subsubsection{Wind Environment Survey}

Measurement was conducted on a clear and cloudless day in November 2019 for a total of 9 test days. The measurement time for each test day was 12:00-17:30. PC-8 Environmental Monitor were used for measurement, where the instruments could simultaneously record the air temperature, relative humidity, wind velocity, wind direction, solar radiation, and 
other microclimatic factors. The data is accurate to three decimal places. Separate devices were mounted on 1.5-m-high tripods and set to record data once per $1 \mathrm{~min}$.

Two to three measuring points were arranged in each residential area according to the actual situation (total of 19 measuring points in 8 residential areas). The measurement points were chosen to cover primary open outdoor spaces, areas close to the geometric center of the space, and the areas least affected by trees and building canopy (Figure 3).

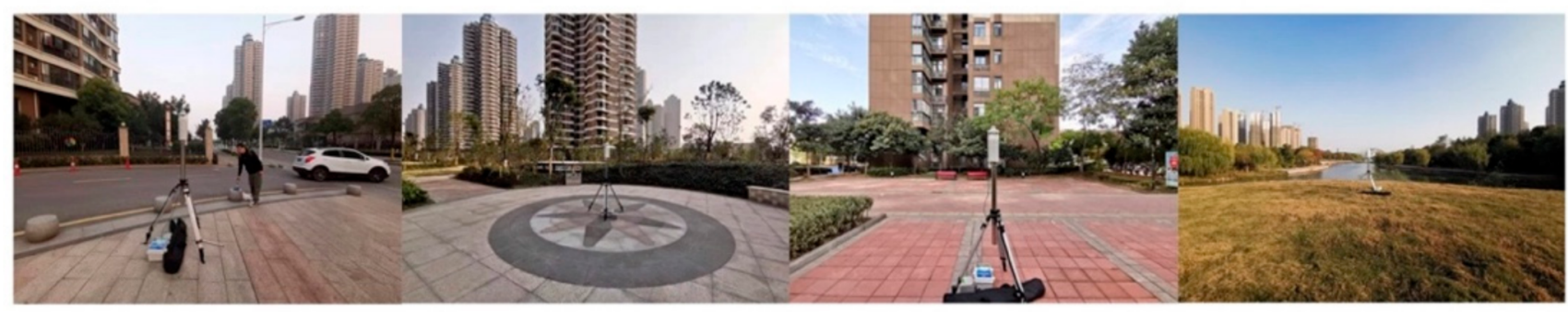

Figure 3. The photos of measurement points during the wind environment survey.

\subsubsection{Calculation of Indicators and Wind Velocity Ratio}

For the calculations of the indicators in the wind environment survey, $\mathrm{Ng}$ [35] recommended a circular calculation range for urban spatial morphology indicators in high density areas. The center point of the calculation range is the measuring point, while the radius of the range is the height of the highest building near the center point. In this paper, considering the building height and layout of each selection area, the radius for calculation was determined to be $100 \mathrm{~m}$ (Figure 4). After that, according to the calculation formulae for $\Psi_{S}, \lambda_{P}, \lambda_{F}, P_{0}, R_{\alpha}$, and $S_{\theta}$, taking 19 measuring points for circle centers, the numerical values for various urban spatial morphology indicators within a radius of $100 \mathrm{~m}$ were calculated.
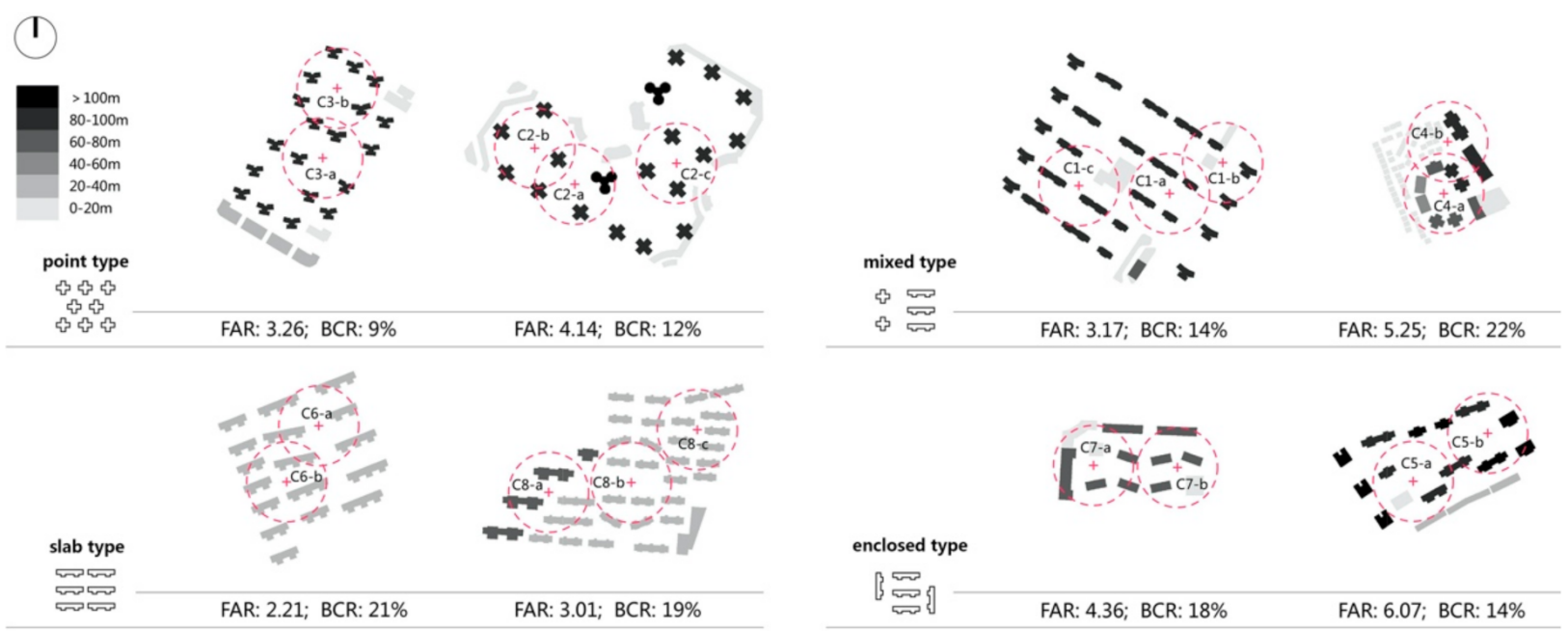

Figure 4. Measuring points arrangements and indicator calculation ranges.

For the wind velocity ratio (WVR), measurements were recorded at each measurement point for two consecutive days during 12:00-17:30 every day without interruption, where data were recorded once every minute. In total, 660 sets of data were collected at each measuring point, and a total of 250,080 sets of data were collected at 19 measuring points and 3 reference points. After that, the values of the measuring points and reference points were used for calculating WVR. The WVRs for each measurement and reference point were taken as 2-day averages to reduce accidental errors. 


\subsection{Simulation Using the CFD Technique}

With the dramatic improvement of computing accuracy, computational fluid dynamics (CFD) has become one of the main tools for analyzing wind fields [36]. CFD is currently widely used in building design, urban wind field analysis, air pollution analysis, and other related research $[37,38]$. It can simultaneously perform comparative analysis among different scenarios, and the simulation results can reflect the entire wind field in a given space, which is impossible to achieve by actual measurement and wind tunnel experiments [37]. In this paper, the simulation procedure started with using the Rhinoceros (version 6.19) software package to create the building geometry, then using ICEM-CFD (version 19.0) for meshing while using an unstructured grid. After that, ANSYS Fluent (version 17.1) was used for simulation.

\subsubsection{Domain Size and Boundary Conditions}

The general block is a non-isolated situation. To simulate the influence of the environment on the ventilation of the real block, a theoretical nine-square grid model representing the geometric background of the city was designed: a $300 \times 300 \mathrm{~m}$ urban block model was placed in the center and surrounded by the same block geometry, while the middle block was taken as the discussion area. To obtain more accurate results, Tominaga recommended the computational domain size for a three-dimensional model [39]. Accordingly, the block boundary was located $5 \mathrm{H}$ (H is the height of the tallest building in the block) from the air inlet boundary and the symmetry boundary of the calculation domain. The block boundary was about $15 \mathrm{H}$ from the air outlet boundary and the height of the calculation domain was about $6 \mathrm{H}$. According to the above requirements, the domain sizes were $1950 \mathrm{~m}$, $1500 \mathrm{~m}$, and $300 \mathrm{~m}$ in the longitudinal (x), lateral (y), and vertical (z) directions, respectively, including all buildings and surrounding areas (Figure 5).

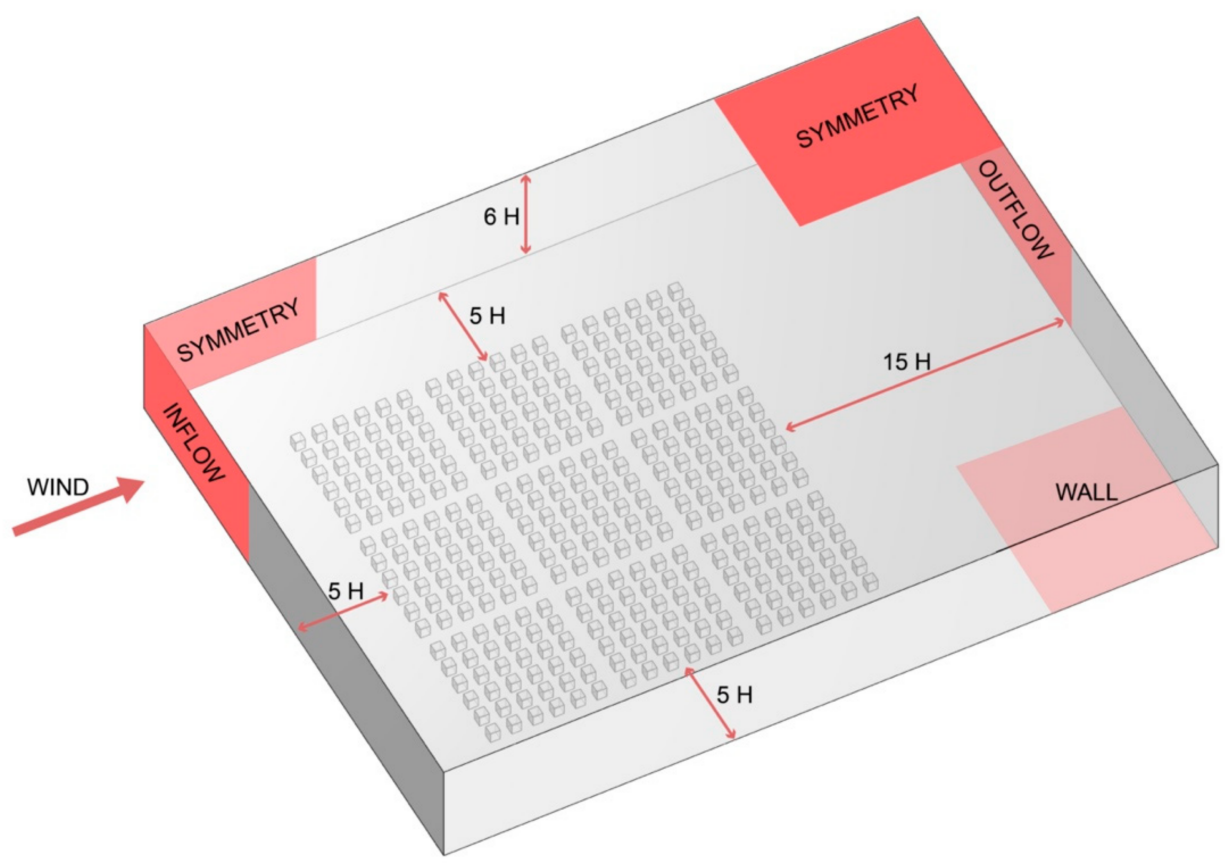

Figure 5. The domain size and boundary conditions in the case study.

For the inflow boundary conditions, the inlet profiles followed the recommendation presented by Richards and Hoxey [40]. The wind direction was set to a southern direction and the reference height wind speed was $2.0 \mathrm{~m} / \mathrm{s}$. A zero static gauge pressure condition was defined as the outflow boundary condition. At the top and lateral boundaries of the computational domain, the symmetry boundary conditions were applied to avoid the wall 
effect. Non-slip wall boundary conditions were set on the ground surfaces and all building surfaces.

\subsubsection{Solution Methods and Convergence Condition}

Fluent is a software package based on finite volume technology, which divides a calculation area into small control volumes to iteratively solve conservation of momentum, mass, and energy equations. In this paper, we chose ANSYS Fluent as a simulation tool.

For the choice of the turbulence model, Cheng et al. compared standard Reynoldsaveraged Navier-Stokes (RANS) equations and Large Eddy Simulation (LES), which are the most popular turbulence models for urban ventilation simulation [41]. Compared with LES, the RANS approach is more commonly used in urban ventilation assessment because of its good results and high computational efficiency with generic urban configurations [39,42-46]. In addition, a series of papers demonstrate the applicability of standard $\mathrm{k}-\varepsilon$ model for urban ventilation simulation [43-46]. Therefore, the standard $\mathrm{k}-\varepsilon$ model was chosen to solve the problem, while the governing equations that were used were those suggested by Cheng et al. [41]. The equations are described as follows, while Table 2 shows the model constants in the simulation method.

$$
\begin{gathered}
\rho(u . \nabla) u=\nabla \cdot\left[-\rho I+\left(\mu+\mu_{T}\right)\left(\nabla u+(\nabla u)^{T}\right)-\frac{2}{3}\left(\mu+\mu_{T}\right)(\nabla \cdot u) I-\frac{2}{3} \rho k I\right]+F \\
\nabla \cdot(\rho u)=0 \\
\rho(u \cdot \nabla) k=\nabla \cdot\left[\left(\mu+\frac{\mu_{T}}{\sigma_{k}}\right) \nabla k\right]+P_{k}-\rho \varepsilon \\
\rho(u \cdot \nabla) \varepsilon=\nabla \cdot\left[\left(\mu+\frac{\mu_{T}}{\sigma_{\varepsilon}}\right) \nabla \varepsilon\right]+C_{e 1} \frac{\varepsilon}{k} P_{k}-C_{e 2} \rho \frac{\varepsilon^{2}}{k} \\
\mu_{T}=\rho c_{\mu} \frac{k^{2}}{\varepsilon} \\
P_{k}=\mu_{T}\left[\nabla u:\left(\nabla u+(\nabla u)^{T}\right)-\frac{2}{3}(\nabla u)^{2}\right]-\frac{2}{3} \rho k \nabla \cdot u
\end{gathered}
$$

$\mu$ the fluid's dynamic viscosity (SI unit: $\mathrm{kg} /(\mathrm{m} \cdot \mathrm{s})$ )

$\mu_{T}$ turbulent viscosity (SI unit: $\mathrm{kg} /(\mathrm{m} \cdot \mathrm{s})$ )

$u$ the velocity field (SI unit: $\mathrm{m} / \mathrm{s}$ )

$\rho$ the density of the fluid (SI unit: $\mathrm{kg} / \mathrm{m}^{3}$ )

$P$ the pressure (SI unit: $\mathrm{Pa}$ )

$k$ turbulent kinetic energy (SI unit: $\mathrm{m}^{2} / \mathrm{s}^{2}$ )

$\varepsilon$ turbulent dissipation rate (SI unit: $\mathrm{m}^{2} / \mathrm{s}^{3}$ )

Table 2. Model constants, which have been experimentally verified and used in the governing equations [40,47-50].

\begin{tabular}{cc}
\hline Constant & Value \\
\hline $\mathrm{C}_{\mu}$ & 0.09 \\
$\mathrm{C} e_{1}$ & 1.44 \\
$\mathrm{C} e_{2}$ & 1.92 \\
$\sigma_{\mathrm{k}}$ & 1.0 \\
$\sigma_{\varepsilon}$ & 1.3 \\
\hline
\end{tabular}

What is more, Franke et al. [51] presented practice guidelines for CFD simulation for flows in urban environments within the COST Action 732 framework, thus presenting guidelines for later studies about urban wind CFD simulations. In this paper, we followed the recommendation of the guidelines. Initializing RANS simulations with uniform velocity, turbulent flow energy, and energy dissipation rate fields typically requires 1500 iterations 
to reach convergence. Calculations were conducted until the desired level of convergence was reached, i.e., the constant residuals of all equations were $10^{-4}$ or less [51,52]. The calculation conditions of Fluent are shown in Table 3.

Table 3. Calculation conditions of Fluent.

\begin{tabular}{ll}
\hline Computational Condition & Setting \\
\hline Computational domain & $1950 \mathrm{~m} \times 1500 \mathrm{~m} \times 300 \mathrm{~m}$ \\
Turbulence model & Standard $\mathrm{k}-\varepsilon$ turbulence model \\
Algorithm for pressure-velocity & SIMPLE \\
Convergence condition & The maximum permissible residual error is $10^{-4}$ \\
Grid resolution & more than 8,000,000 volume grids \\
Total number of iterations & 1500 \\
\hline
\end{tabular}

\subsubsection{Grid Size and Independence}

A grid sensitivity analysis was conducted to ensure the grid independence of the CFD simulation results. Franke et al. [53] suggested that at least 10 cells should be used on each side of the building when the grid is divided, and at least 3 cells should be used at a height of 1.5- $2 \mathrm{~m}$ above the ground. Thus, four grids were made by increasing the resolution from Grid A (about 3,610,000 cells), Grid B (about 5,270,000 cells), Grid C (about 8,220,000 cells) to Grid D (about 11,970,000 cells) (Figure 6a-d). The increasing ratio of gird resolution is about a factor 1.5, which was suggested by Celik et al., that the grid refinement factor should be greater than 1.3 [54]. The results of these four grids were compared on the WVR $\left(\mathrm{U} / \mathrm{U}_{\text {ref }}\right)$ of the centerline in the center block (Figure 6e). It is notable that $\mathrm{U}$ is the wind velocity at $1.5 \mathrm{~m}$, and that $U_{\text {ref }}=2 \mathrm{~m} / \mathrm{s}$ is the reference height wind velocity. Figure $5 \mathrm{e}$ indicates a large difference between Grid A, B, and C, but a relatively small difference between Grid C and D. Considering the computational efficiency, the grid resolution of Grid C was used for the remaining cases: the grid size in the discussion area was selected as $1 \mathrm{~m}$, while the number of volume grids of each model is larger than $8,000,000$.
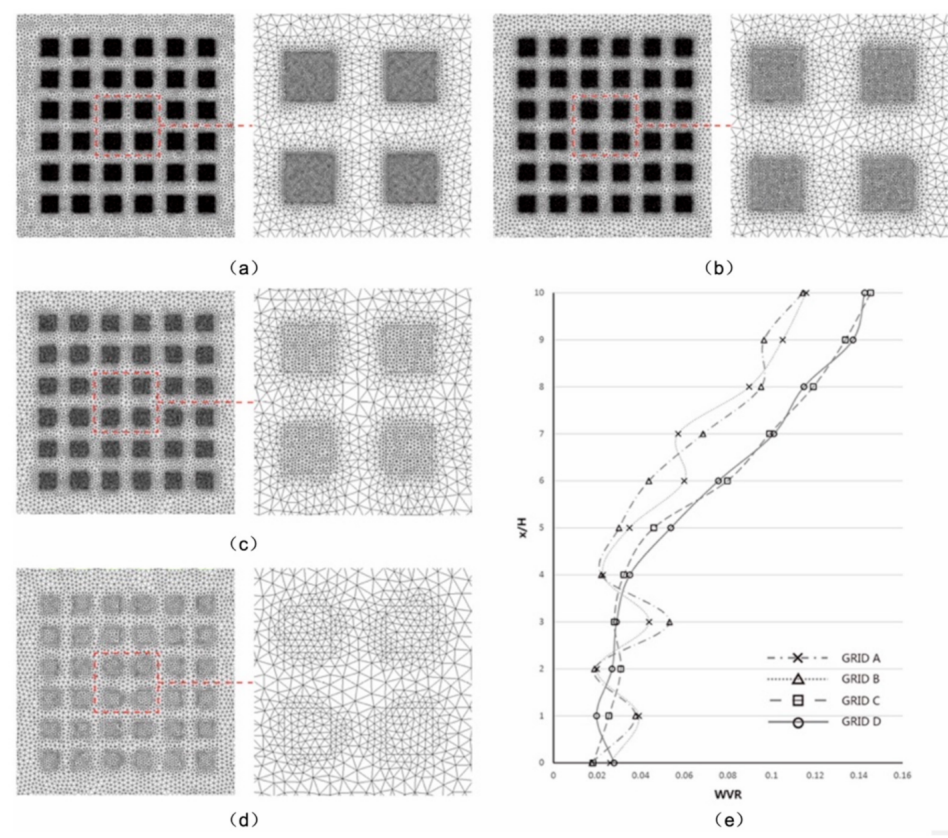

Figure 6. Grid sensitivity analysis. (a) the center block of Grid A: about 3,610,000 cells; (b) the center block of Grid B: about 5,270,000 cells; (c) the center block of Grid C: about 8,220,000 cells; (d) the center block of Grid D: about 11,970,000 cells; (e) The comparison of the wind velocity ratio (WVR) along the centerline of the block for the four girds. 


\subsubsection{Validation of the CFD Simulation}

In this paper, the CEDVAL (Compilation of Experimental Data for Validation of Microscale Dispersion Models) database is selected for the model evaluation. The CEDVAL experiments were carried out at Hamburg University, which include mean wind field and turbulence for single buildings and clusters of buildings. This database is widely used for the development and evaluation of microscale numerical models [55-58].

The B1-1 wind tunnel experiments in CEDVAL were chosen for evaluating the performance of the CFD simulation, which is similar to the working conditions of our study. The atmospheric boundary layer was modeled at a scale of 1:200, while 2D flow measurements were carried out in 4 vertical and 1 horizontal measurement plane in the B1-1. Figure 7a shows the experimental layout of the B1-1. The model configurations were set to match those in the wind tunnel experiment, while the CFD calculation conditions are the same as that in Section 3.2.2. After that, we thoroughly validated our CFD results with wind tunnel results. The streamwise wind velocity ratio of point I, point II, point III are compared in Figure $7 \mathrm{~b}-\mathrm{d}$. As can be seen, the CFD simulation results has good agreement with experimental results. The Root Mean Square Error (RMSE) of CFD and wind tunnel results in point I, point II and point III are $0.0932,0.0917$, and 0.1037 , respectively, the correlation coefficient of which are $0.9660,0.9682$, and 0.9902 , respectively, which indicate that the standard $k-\varepsilon$ model can predict the velocity profiles generally well. Therefore, the model and calculation conditions shown in Section 3.2.2 were used for the remaining cases.
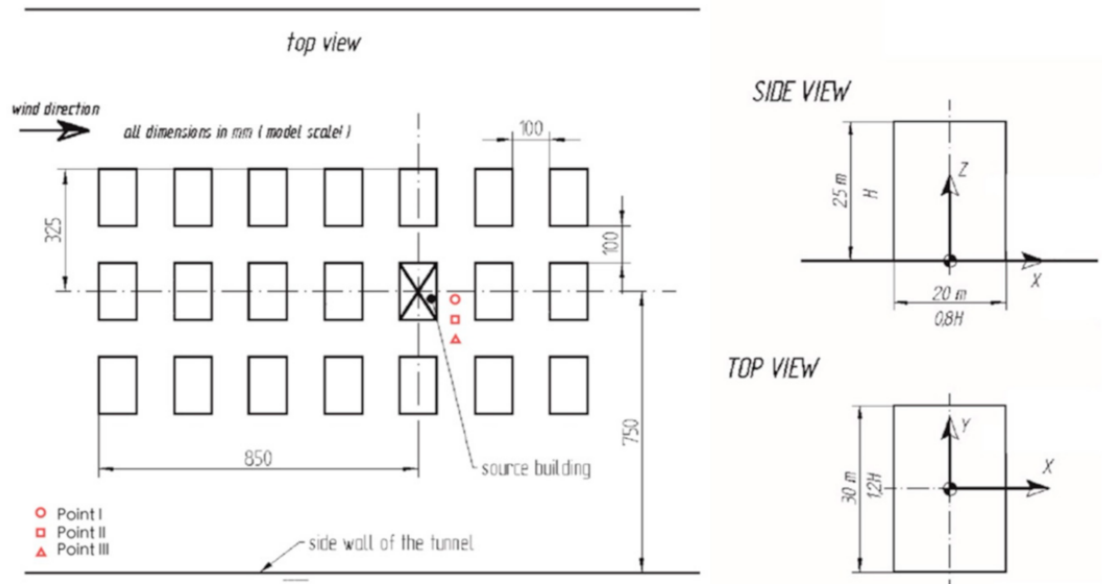

TOP VIEW

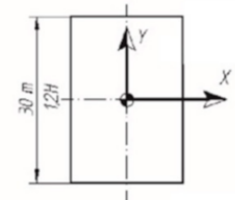

(a)

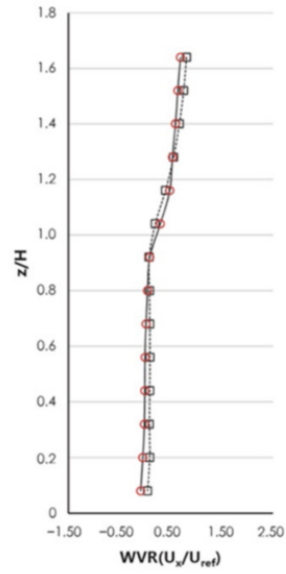

(b)

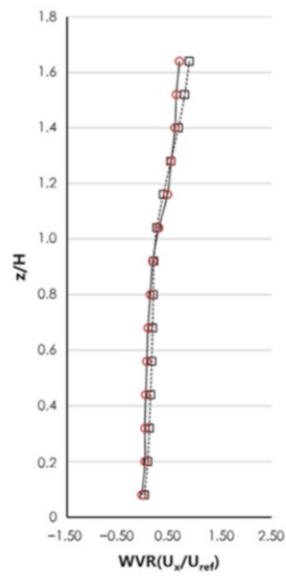

(c)

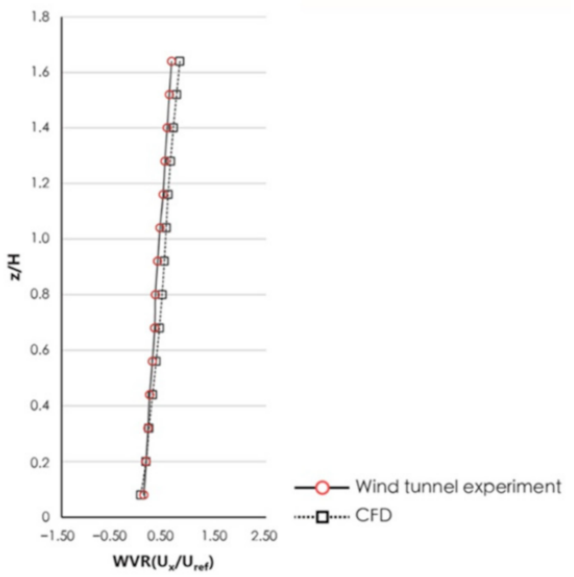

(d)

Figure 7. The validation of the computational fluid dynamic (CFD) simulation. (a) The wind tunnel experimental layout of the B1-1, provided by the CEDVA experiments Database; (b-d) the comparison of streamwise WVR in CFD results and wind tunnel results at point I, point II, point III, respectively. 


\subsubsection{Calculation of Indicators and Wind Velocity Ratio}

To simulate the influence of the environment on the ventilation of the real block, an idealized model consisting of nine basic blocks in the plot area is considered, where the $300 \times 300 \mathrm{~m}$ urban block model is placed in the center and surrounded by the same block geometry. As shown in Figure 8, the center block model is the area where the urban spatial morphology indicators are calculated, while the wind velocity in the street of center block was used for calculating WVR $\left(\mathrm{U} / \mathrm{U}_{\text {ref }}\right)$. Note that $\mathrm{U}$ is the wind velocity at $1.5 \mathrm{~m}$, and that $\mathrm{U}_{\text {ref }}=2 \mathrm{~m} / \mathrm{s}$ is the reference height wind velocity.
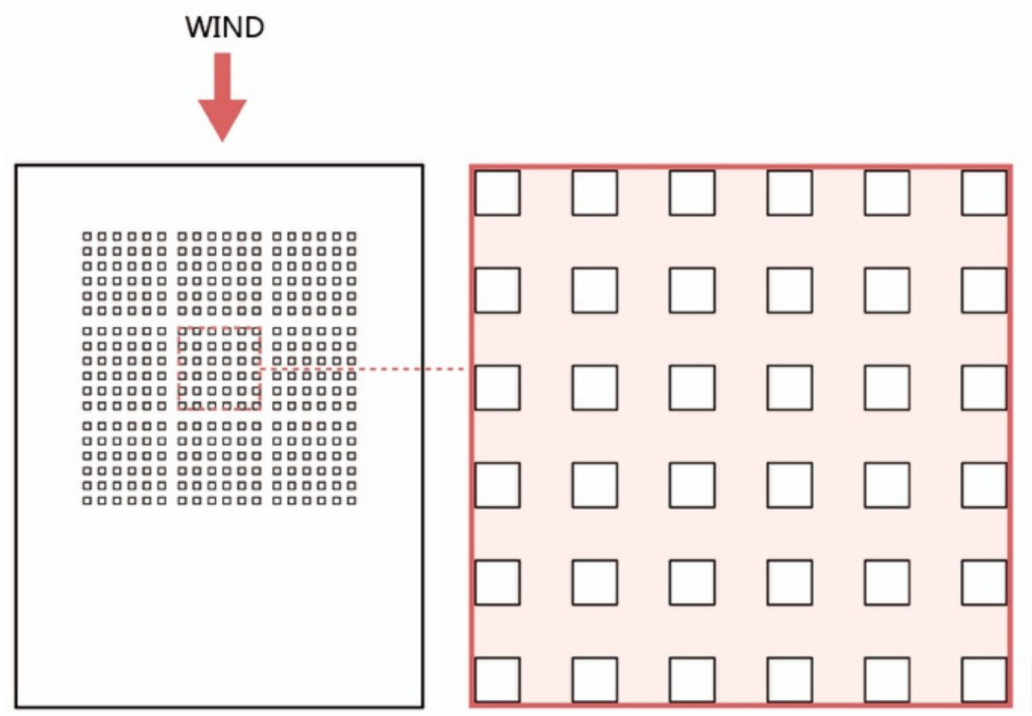

The calculation area of indicators

The calculation area of WVR

Figure 8. The calculation area of indicators and WVR.

\section{Results and Discussion}

\subsection{Measurements Results}

According to the wind environment data collection based on real urban morphologies, 660 sets of data were collected at each measuring point, and a total of 250,080 sets of data were collected at 19 measuring points and 3 reference points. The WVRs at $1.5 \mathrm{~m}$ height for each measuring point and reference point were taken as a 2-day averages to reduce accidental errors. The statistical results for average wind velocity and average wind velocity ratio (WVR) at each measuring point and corresponding reference point are shown in Figure 9.

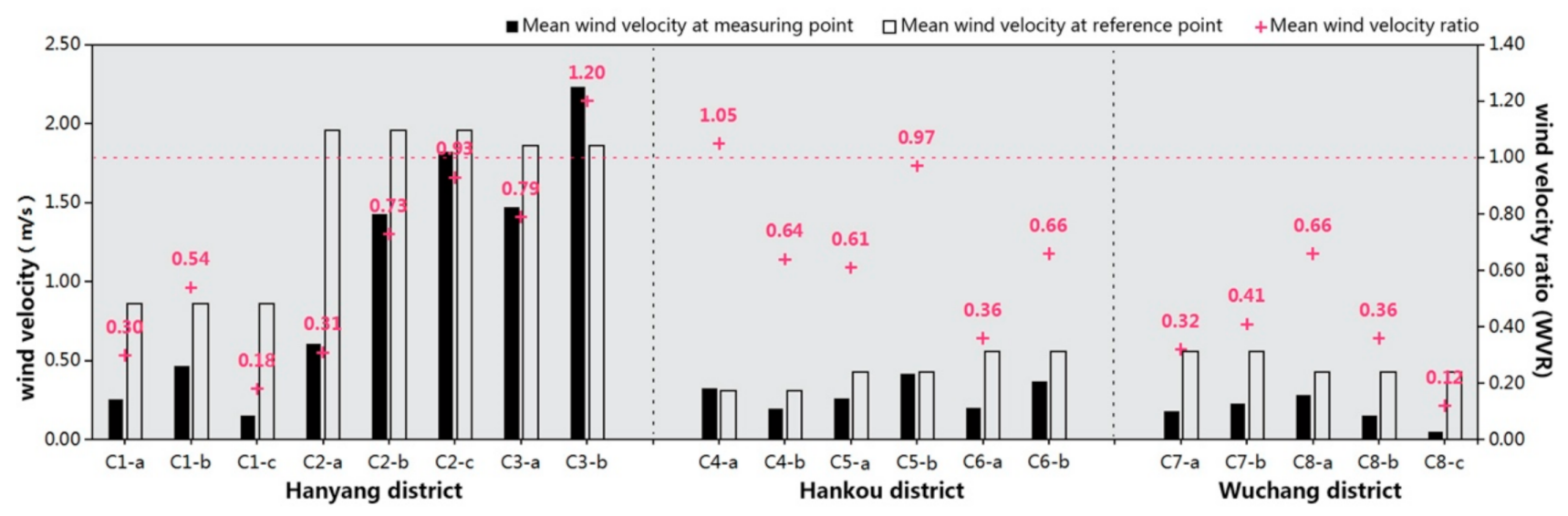

Figure 9. Average wind velocities and average wind velocity ratios. 


\subsubsection{Analysis on the Effectiveness of Urban Spatial Morphology Indicators}

According to the calculation formulae for the SVF, $\lambda_{P}, \lambda_{F}, P_{0}, R_{\alpha}$, and $S_{\theta}$, the values of various urban spatial morphology indicators around the 19 measurement points were respectively calculated. On this basis, the correlations between the WVR and urban spatial morphology indicators were analyzed with different blocks (19 samples were provided from 19 measurement points). The analysis results are shown in Table 4. From this, we can find that, with a complex and changeable realistic urban morphology, the correlations between various urban spatial morphology indicators and pedestrian height WVRs are very low; however, $\mathrm{S}_{\theta}$ and $\mathrm{P}_{0}$ present a weak correlation, while the other indicators all have no correlation with the WVR.

Table 4. Correlation rankings between urban spatial morphology indicators and pedestrian height wind velocity ratios.

\begin{tabular}{cccc}
\hline Correlation Ranking & Urban Spatial Morphology Indicators & $\mathbf{R}$ & $\mathbf{R}^{\mathbf{2}}$ \\
\hline 1 & Sinuosity $\left(\mathrm{S}_{\theta}\right)$ & -0.5414 & 0.2931 \\
\hline 2 & Porosity $\left(\mathrm{P}_{0}\right)$ & 0.4373 & 0.1912 \\
\hline 3 & frontal area density $\left(\lambda_{\mathrm{F}}\right)$ & -0.2395 & 0.0573 \\
\hline 4 & sky-view factor $(\mathrm{SVF})$ & 0.2356 & 0.0555 \\
\hline 5 & plan area density $\left(\lambda_{\mathrm{P}}\right)$ & -0.1601 & 0.0256 \\
\hline 6 & relative rugosity $\left(\mathrm{R}_{\alpha}\right)$ & -0.0547 & 0.0030 \\
\hline
\end{tabular}

According to statistical theory, while the absolute value of correlation coefficient $\mathrm{R}$ is within the approximate range of $0.8-1.0$, it is believed that the two have a strong correlation; between 0.5 and 0.8 , it can be regarded as moderate correlation; between 0.3 and 0.5 , it can be regarded as weak correlation; and, when below 0.3 , no correlation can be considered.

\subsubsection{Influence of Building Height Difference on Indicator Effectiveness}

Based on the assumptions detailed above, SVF, $\lambda_{P}$, and $\lambda_{F}$, which are based on a geometric simplified model, may not be suitable for blocks with high height variations. Therefore, in this series, the statistical results containing all 19 samples were set as a benchmark group. Among them, 13 samples with no elevation difference between buildings and 6 samples with elevation difference above $10 \mathrm{~m}$ were set as 2 control groups, respectively. This was carried out in order to compare the correlation between WVR and SVF, $\lambda_{\mathrm{P}}$, and $\lambda_{\mathrm{F}}$ under different conditions in order to verify whether large height differences for buildings within the same block are the main factor affecting the effectiveness of this group of indicators.

It can be seen from Figure 10 that the correlation between SVF and WVR did not improved by excluding samples with a height difference (the correlation coefficient dropped from 0.2356 to 0.1328 ). This does not conform with the above conjecture, indicating that there are other factors affecting its effectiveness.

Figure 11 shows that the correlation between $\lambda_{\mathrm{P}}$ and WVR improved (the correlation coefficient improved from -0.1601 to -0.3930 ) after excluding samples with a height difference, but the correlation was still weak. This suggests that the effectiveness of $\lambda_{P}$ could be affected by building height differences, but the most suitable type of block has not been identified.

As can be seen from Figure 12, the correlation between $\lambda_{\mathrm{F}}$ and WVR increased by $196.45 \%$ (from -0.2395 to -0.0 .7100 ) after excluding samples with a height difference, which can be considered as a moderate correlation. In the groups with a height difference, however, the correlation decreased significantly (correlation coefficient of -0.1983 ). This suggests that height changes within a block represent one of the main factors affecting the effectiveness of $\lambda_{F}$, and under the condition that the building height in the block is basically the same, $\lambda_{\mathrm{F}}$ can be regarded as an important control indicator. 


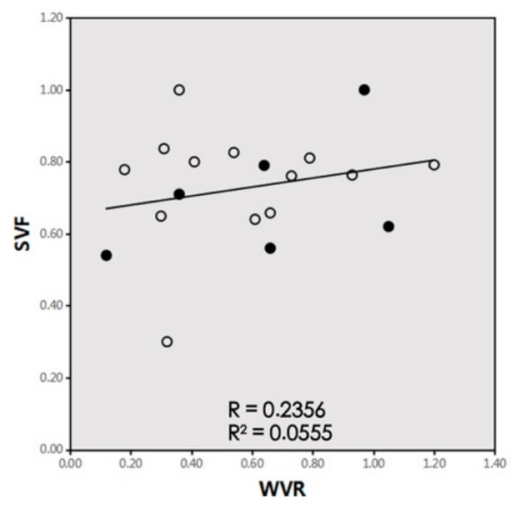

(a)

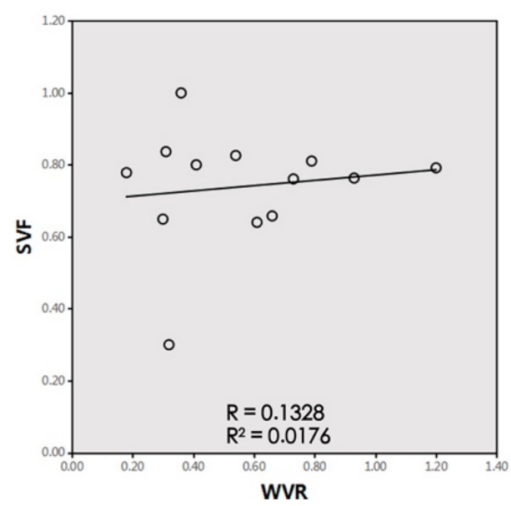

(b)

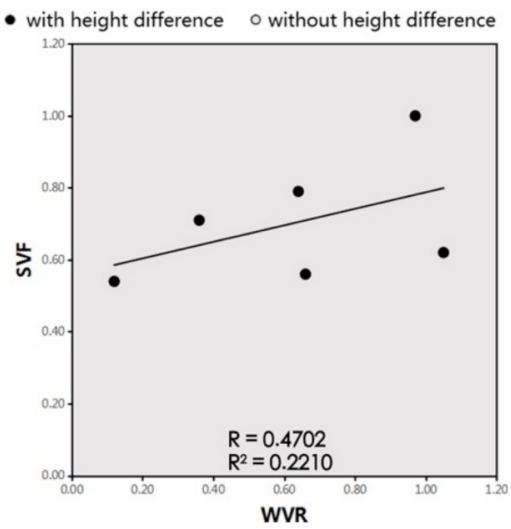

(c)

Figure 10. Scatter plots of SVF and WVR: (a) SVF benchmark group; (b) scatter plots without a height difference; (c) scatter plots with a height difference.

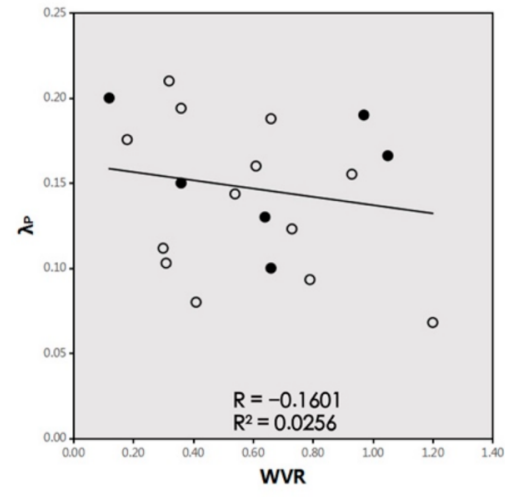

(a)

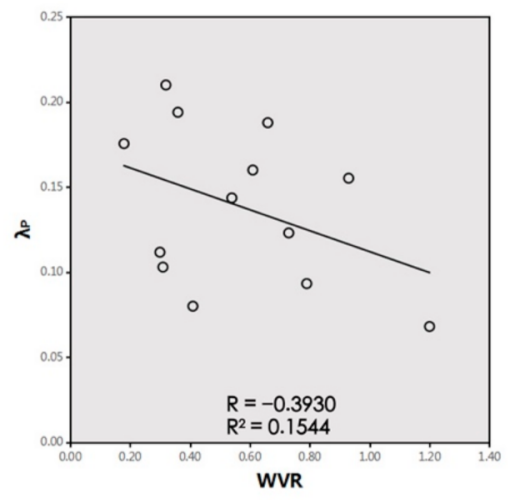

(b)

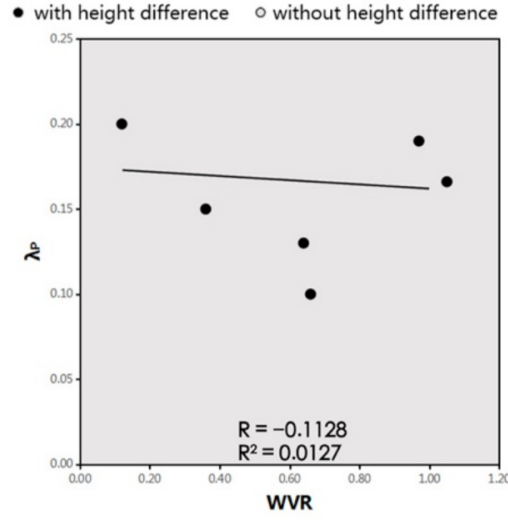

(c)

Figure 11. Scatter plots of $\lambda \mathrm{P}$ and WVR: (a) $\lambda \mathrm{P}$ benchmark group; (b) scatter plots without a height difference; (c) scatter plots with a height difference.

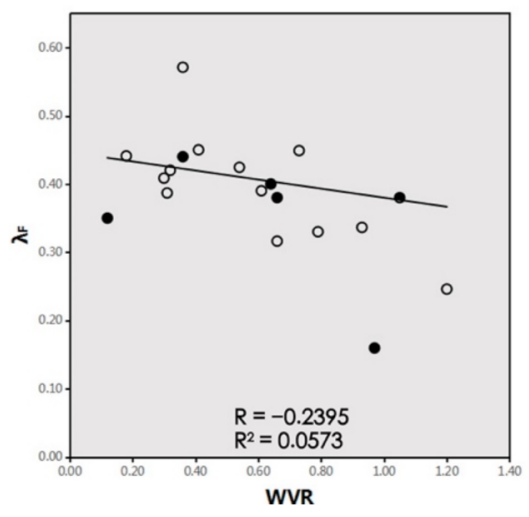

(a)

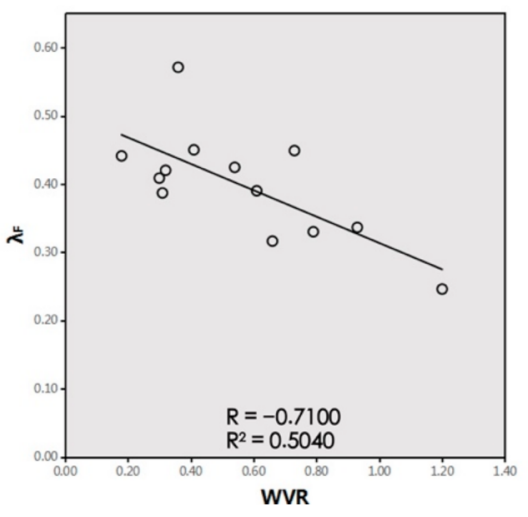

(b)

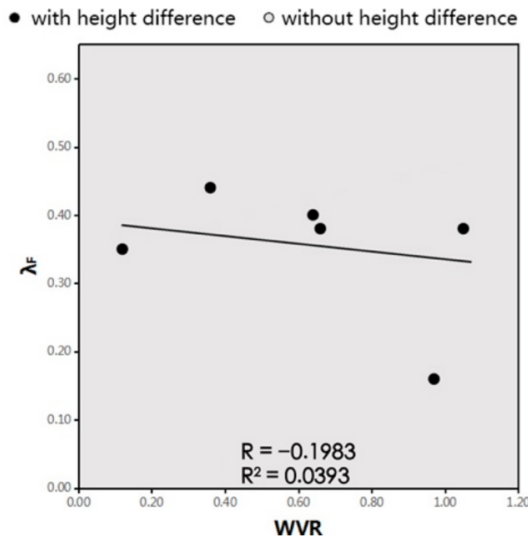

(c)

Figure 12. Scatter plots of $\lambda_{F}$ and WVR: (a) $\lambda_{F}$ benchmark group; (b) scatter plots without a height difference; (c) scatter plots with a height difference. 


\subsubsection{Influence of the Depth of Street Canyons on Indicator Effectiveness}

According to the previous conjectures, for $P_{0}, R_{\alpha}$, and $S_{\theta}$, these three indicators are limited to the evaluation of internal air flow in porous media and thus may not be applicable in shallow street canyons. Accordingly, in this series, the correlation statistical results containing all 19 sample measurement points were set as the benchmark group and were divided into two control groups according to the street canyon depths. Among them, there were 13 samples in the deep street canyon group (all street canyons with an aspect ratio greater than 1.2) and 6 samples in the shallow street canyon group (all street canyons with an aspect ratio less than 0.9). By comparing the changes in the correlation between WVR and $P_{0}, R_{\alpha}$, and $S_{\theta}$ under different conditions, it was verified whether the street canyon depth was the main factor affecting the effectiveness of this group of indicators.

As can be seen from Figure 13, the correlation between $R_{\alpha}$ and WVR was not improved by excluding samples with shallow canyons (the correlation coefficient decreased from -0.0547 to -0.0464$)$. This does not follow the above conjecture, indicating that there are other factors affecting the effectiveness.

According to Figure 14, the correlation between $\mathrm{P}_{0}$ and WVR increased by $108.96 \%$ (the correlation coefficient increased from 0.4373 to 0.9138 ) after excluding samples with shallow street canyons, which could be considered as high correlation. On the other hand, in the shallow street canyon group, the correlation decreased significantly (correlation coefficient: 0.0925). This indicates that the street canyon depth is the most important factor in terms of affecting the effectiveness of $\mathrm{P}_{0}$. In addition, in the case of deep street canyons, $\mathrm{P}_{0}$ can effectively predict wind environments within blocks.

According to Figure 15, the correlation between $S_{\theta}$ and WVR presented a weak correlation with little change in the benchmark group and the two control groups (correlation coefficients of $0.5414,0.5810$, and 0.4518 , respectively). The correlation did not conform with the above conjecture, indicating that there are other factors affecting its effectiveness.

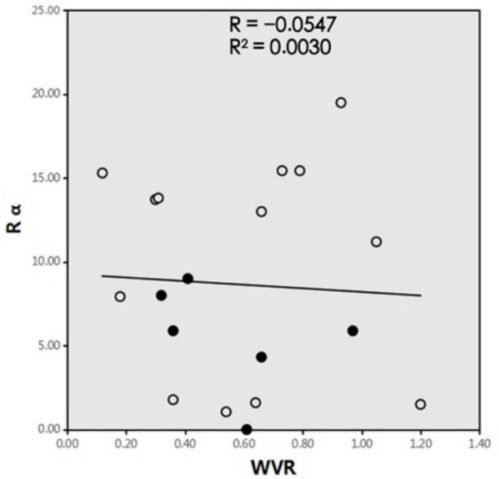

(a)

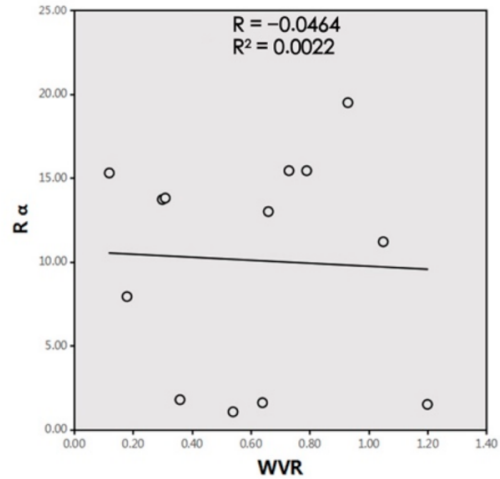

(b)

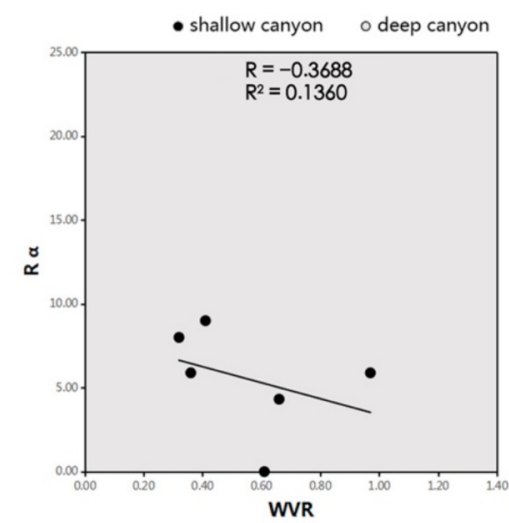

(c)

Figure 13. Scatter plots of $R_{\alpha}$ and WVR: (a) $R_{\alpha}$ benchmark group; (b) scatter plots with deep canyons; (c) scatter plots with shallow canyons. 


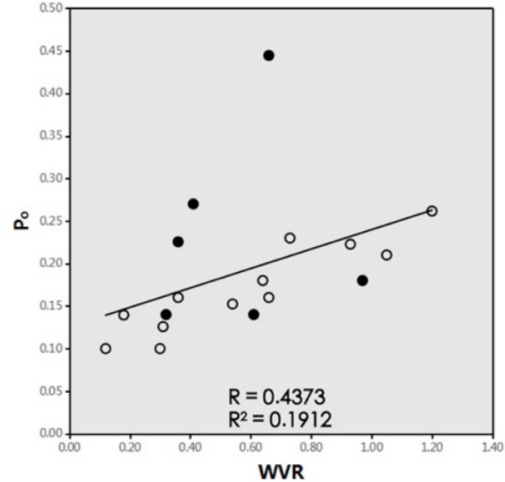

(a)

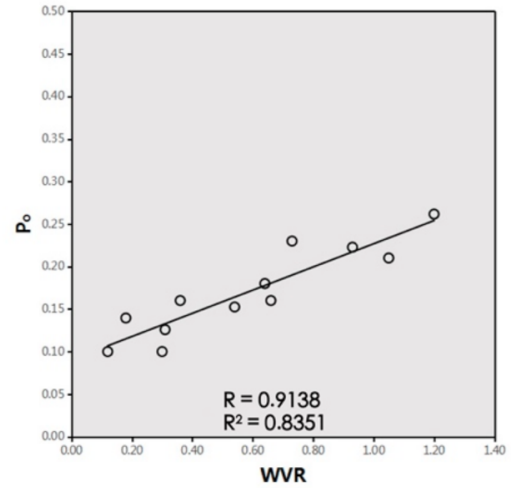

(b)

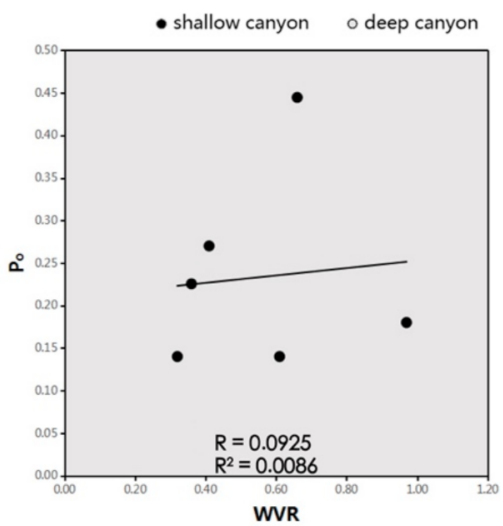

(c)

Figure 14. Scatter plots of $\mathrm{P}_{0}$ and WVR: (a) $\mathrm{P}_{0}$ benchmark group; (b) scatter plots with deep canyons; (c) scatter plots with shallow canyons.

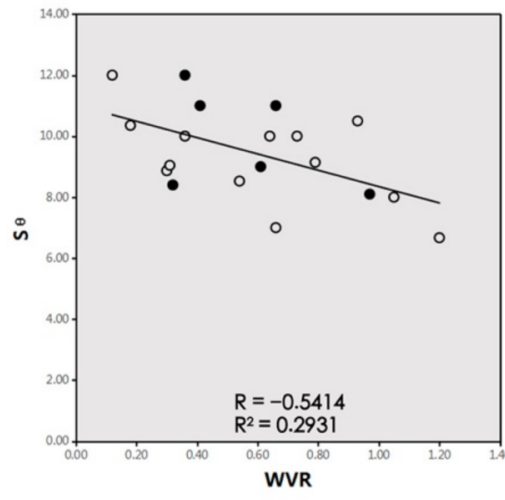

(a)

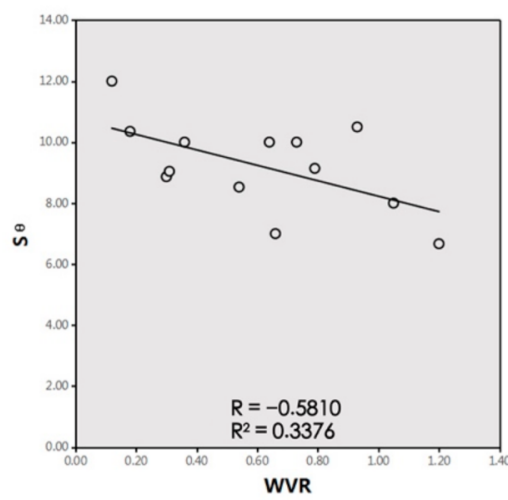

(b)

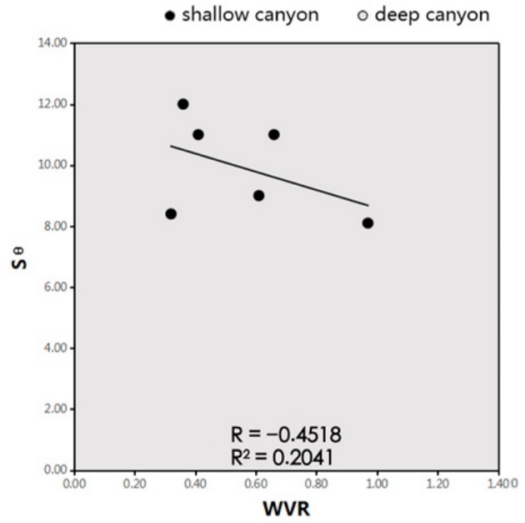

(c)

Figure 15. Scatter plots of $S_{\theta}$ and WVR: (a) $S_{\theta}$ benchmark group; (b) scatter plots with deep canyons; (c) scatter plots with shallow canyons.

\subsection{CFD Simulation Results}

Simplified hypothetical block models for the assessment of block wind environment have been widely used in research, since these models can eliminate the restrictions of specific locations, increasing the variability of analysis. Through theoretical prediction and practical verification (see Section 4.1), we have found that $\lambda_{\mathrm{F}}$ is not suitable for blocks with large height differences, while $\mathrm{P}_{0}$ cannot be applied to shallow canyons. Therefore, two problems were quantified through numerical simulation: (1) What difference in height would make $\lambda_{\mathrm{F}}$ ineffective? (2) How shallow canyon depth makes $\mathrm{P}_{0}$ ineffective? This paper used a similar modeling method in the wind environment simulation, selecting six building types, namely, scatter, courtyard, slab, staggered, strip, and scatter with strip buildings (Figure 16), representing the typical building layouts for blocks in contemporary cities. Standard deviations of building height variations were used to describe the change of building heights in the blocks and street canyon aspect ratios were used to describe the depths of the street canyons in the blocks. As shown in Figure 17a,b, we explored the predictability of $\lambda_{F}$ on the wind environment by changing the height difference of the buildings in the block (the height differences were $0,5,10,15$, and $20 \mathrm{~m}$ ), and explored the 
predictability of $\mathrm{P}_{0}$ on the wind environment by changing the aspect ratios of the buildings in the block (the aspect ratios were $0.4,1,1.6,2.2$, and 2.8).
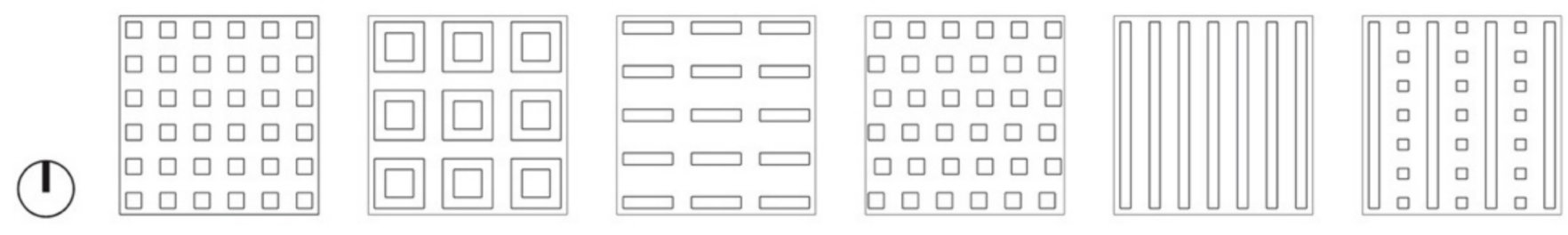

Figure 16. The six building types for the computational fluid dynamics (CFD) simulation.

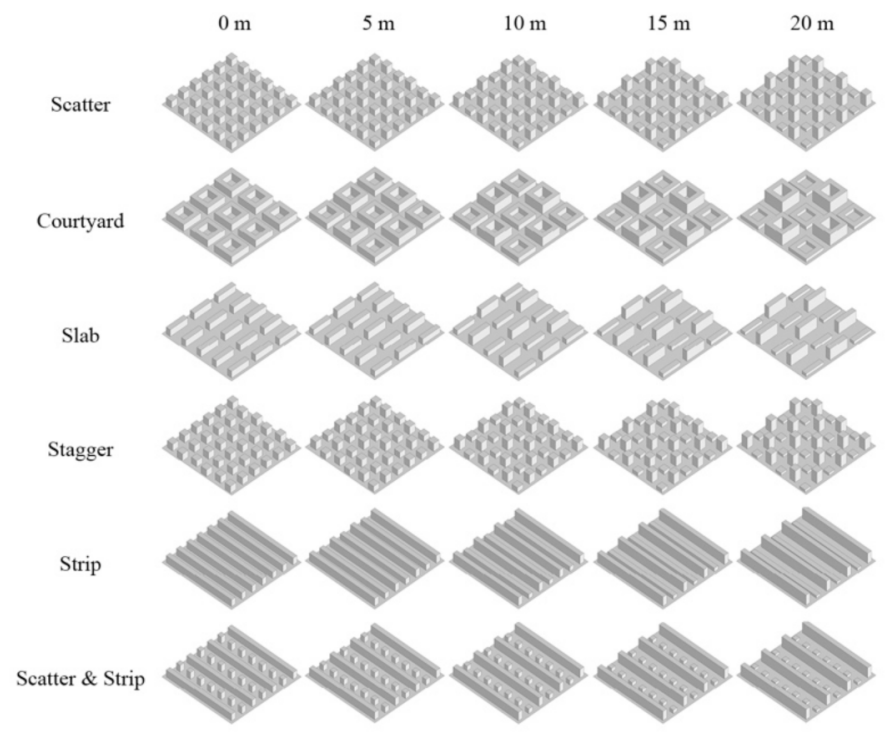

(a)

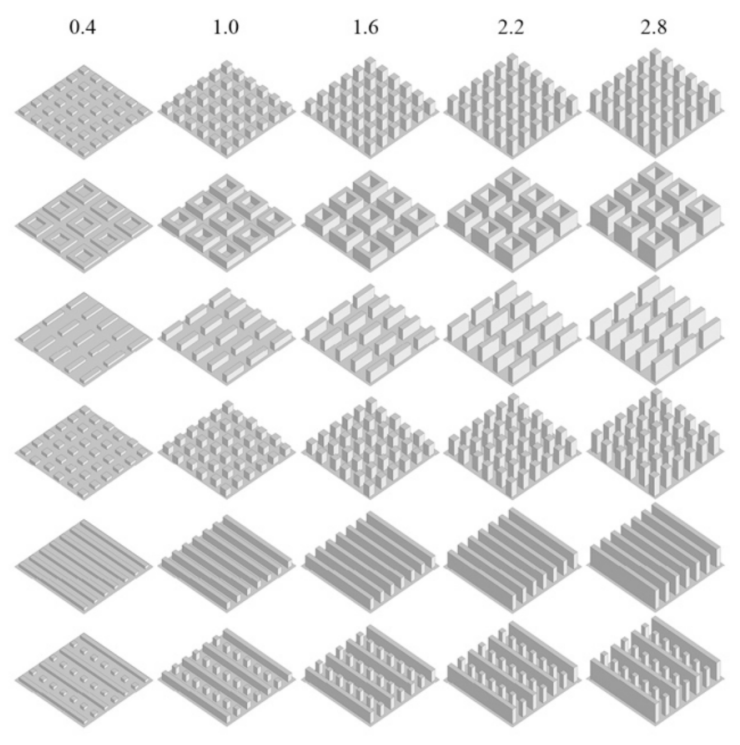

(b)

Figure 17. (a) The standard deviations of building height variations for six building types. (b) The street canyon aspect ratio variations for six building types.

To study the influence of height differences and aspect ratios on the predictive accuracy of morphological indicators $\lambda_{F}$ and $P_{0}$, this paper used a k- $\varepsilon$ turbulence model to conduct CFD simulation for the wind environments around the buildings. The boundary and calculation conditions shown in Section 3.2 were used for the cases. Figure 18a,b respectively show the comparative analysis of the wind environment at $1.5 \mathrm{~m}$ with different height differences and different aspect ratios for six typical building layouts in blocks. According to the calculation formulae for $\lambda_{F}$ and $P_{0}$, values for each urban spatial morphology index were calculated. Based on the calculation results, Pearson correlation was used to calculate the correlation between $\lambda_{\mathrm{F}}$ and WVR under different height differences and the correlation between $\mathrm{P}_{0}$ and WVR under different aspect ratios. The results are given as follows. 


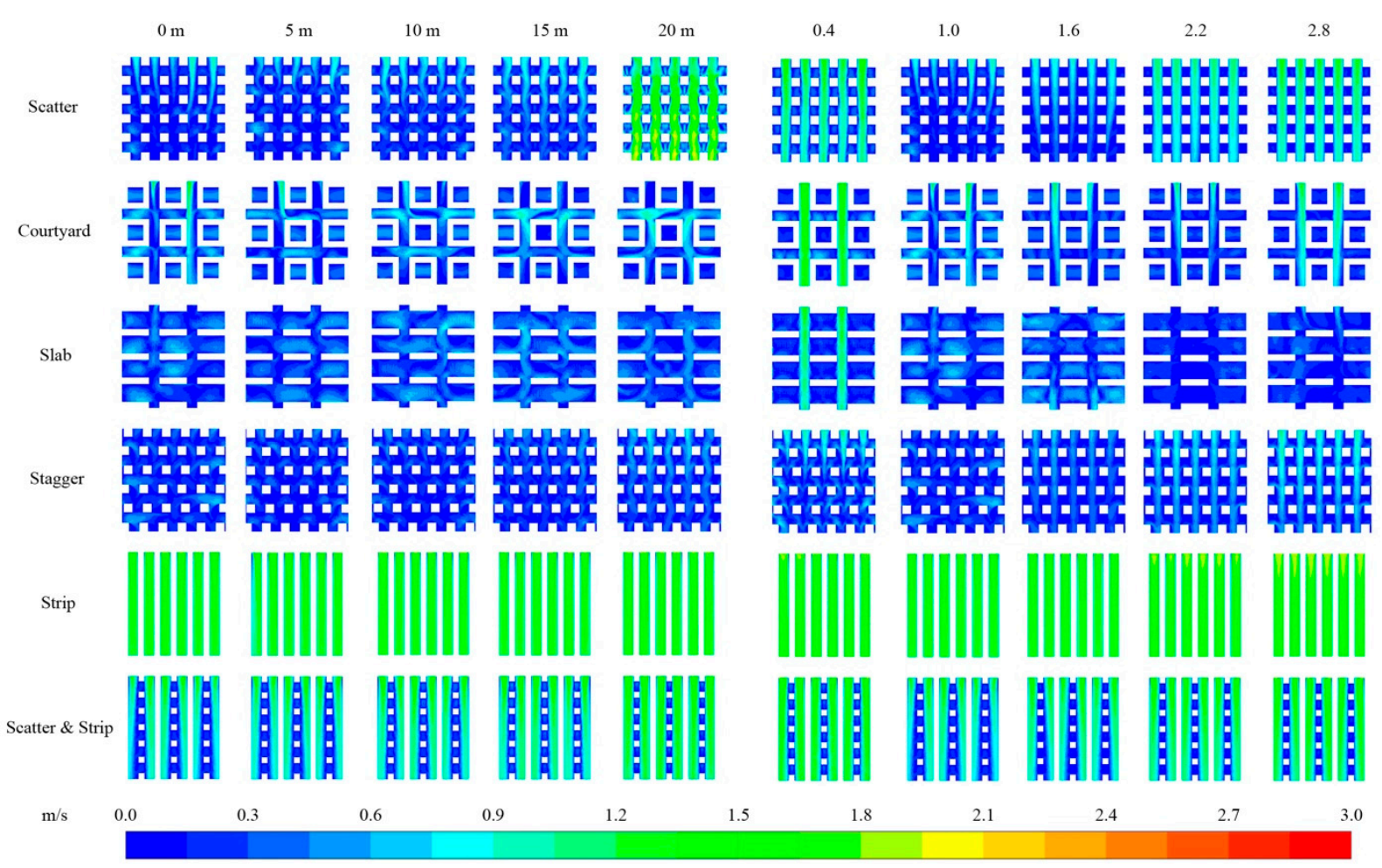

(a)

(b)

Figure 18. (a) Simulation results for the standard deviations of building height variations. (b) Simulation results of the street canyon aspect ratio variations.

\subsubsection{Influence of Height Differences on $\lambda_{\mathrm{F}}$}

Figure 19a shows the correlation between $\lambda_{\mathrm{F}}$ and WVR under different height differences. $\lambda_{F}$ and WVR have a strong and negative correlation (correlation coefficient: $\mathrm{R}=-0.8594)$. This shows that $\lambda_{\mathrm{F}}$ performs well under the condition of ideal block simulation.

Figure 19b-f shows the correlation between $\lambda_{F}$ and WVR when the standard deviations of building height variation were $0,5,10,15$, and $20 \mathrm{~m}$. When discussing different height differences, the correlations at $0,5,10$, and $15 \mathrm{~m}$ are improved $(|\mathrm{R}|>0.89)$, which shows strong correlation, while $\lambda_{\mathrm{F}}$ had the highest correlation with $\mathrm{WVR}(|\mathrm{R}|=0.9350)$ when there was no height difference; however, when the height difference was $20 \mathrm{~m}$, the correlation decreased $(|\mathrm{R}|=0.7632)$, showing a moderate correlation. The simulation results show that the change of the height difference in a block can affect the predictability of $\lambda_{F}$ for a given wind environment. When there was no height difference, $\lambda_{F}$ had the best performance, and $\lambda_{F}$ could accurately predict the wind environment of a block when the standard deviation of the building height variation was less than $15 \mathrm{~m}$; however, $\lambda_{\mathrm{F}}$ could not accurately produce predictions when the standard deviation was greater than $20 \mathrm{~m}$. In general, the correlation between $\lambda_{\mathrm{F}}$ and WVR decreased as the building height difference within a block increased. 


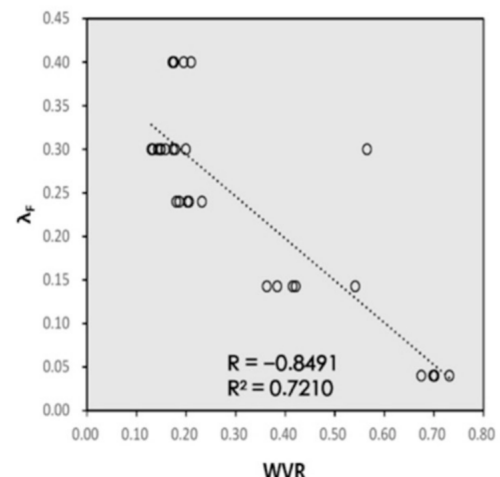

(a)

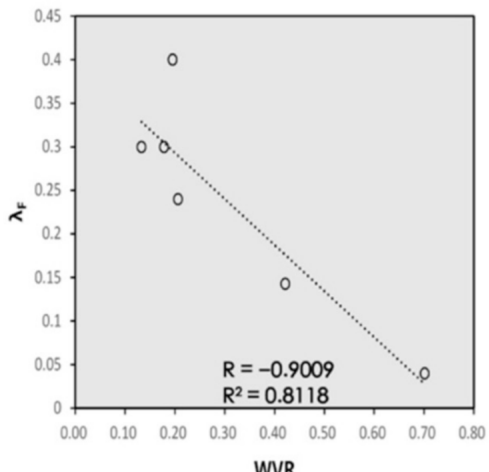

(d)

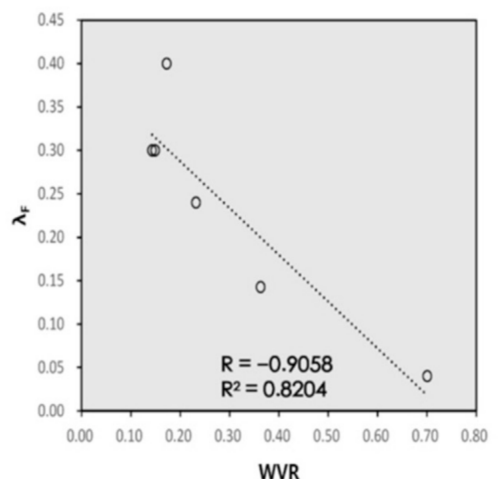

(b)

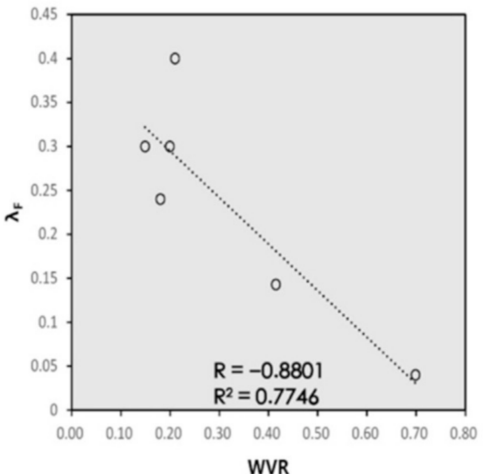

(e)

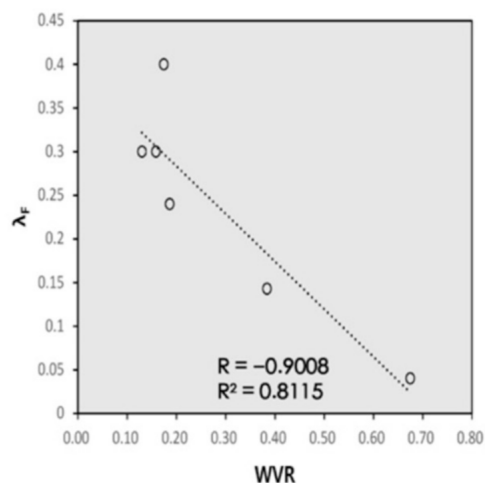

(c)

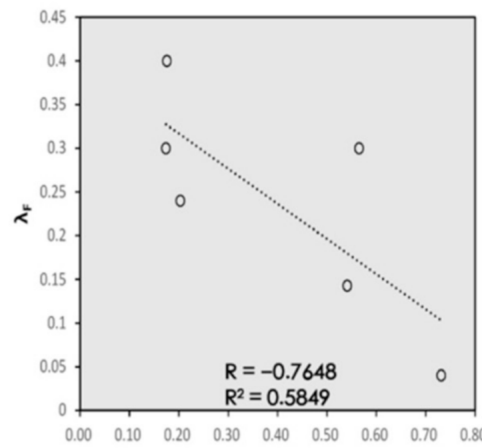

WVR

(f)

Figure 19. Scatter plots and correlation of $\lambda_{F}$ and WVR in terms of different standard deviations of building height variation.

(a) Standard deviation is $0-20 \mathrm{~m}$; (b) standard deviation is $0 \mathrm{~m}$; (c) standard deviation is $5 \mathrm{~m}$; (d) standard deviation is $10 \mathrm{~m}$; (e) standard deviation is $15 \mathrm{~m}$; (f) standard deviation is $20 \mathrm{~m}$.

\subsubsection{Influence of Street Canyon Depth on $\mathrm{P}_{0}$}

Figure 20a shows the correlation between $\mathrm{P}_{0}$ and WVR for different street canyon depths. The correlation between $\mathrm{P}_{0}$ and WVR was moderately positive (correlation coefficient: $R=0.6829$ ), which shows that $P_{0}$ cannot accurately predict the wind environment of blocks with different street canyon depths.

Figure 20b-f shows the correlation between $\mathrm{P}_{0}$ and WVR with street canyon aspect ratios of $0.4,1.0,1.6,2.2$, and 2.8, respectively. When the aspect ratios were 2.2 and 2.8, the correlation between $P_{0}$ and WVR greatly improved $(|R|>0.8)$, showing a strong correlation. For the aspect ratios of $0.4,1.0,1.6$, the correlation decreased $(|\mathrm{R}|<0.7)$, showing moderate correlation. The simulation results show that the street canyon depths in the block will affect the predictability of $\mathrm{P}_{0}$ in terms of the wind environment. The wind environment of the block could be accurately predicted by $\mathrm{P}_{0}$ when the street canyon aspect ratio was greater than 2.2, while it could not be predicted accurately when the aspect ratio was less than 1.6. In general, the shallower the canyon in a block is, the lower the correlation between $\mathrm{P}_{0}$ and WVR will be. 


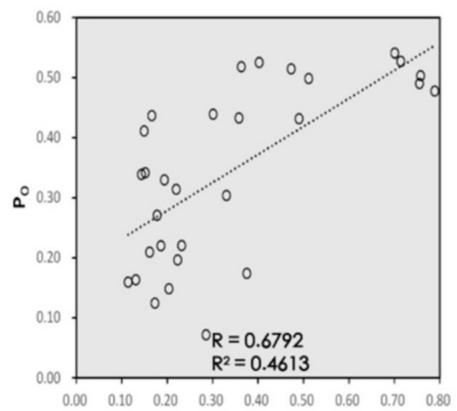

WVR

(a)

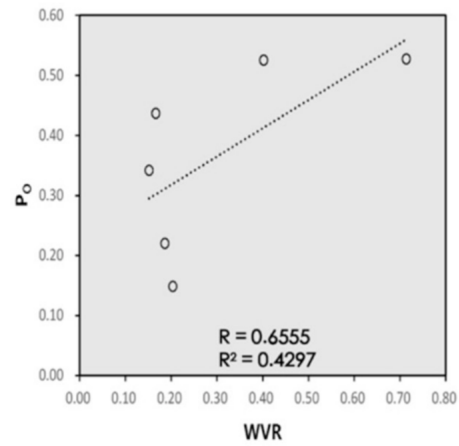

(d)

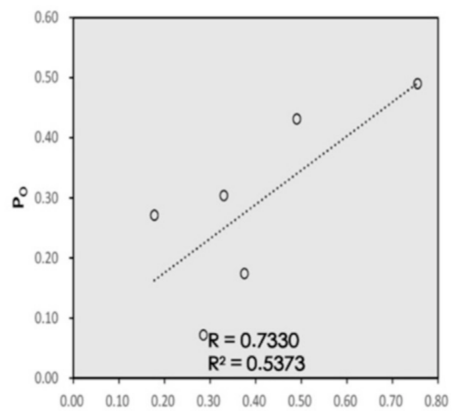

WVR

(b)

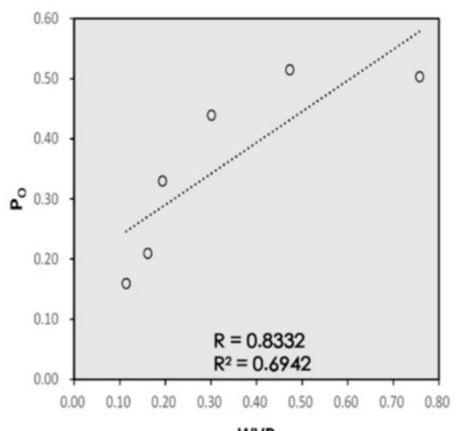

(e)

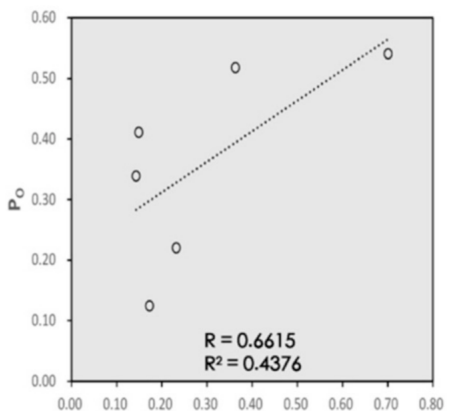

WVR

(c)

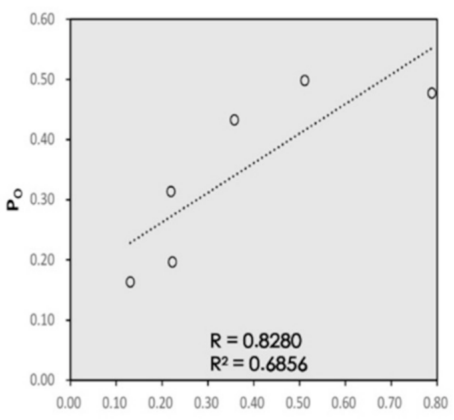

WVR

(f)

Figure 20. Scatter plots and correlations of $\mathrm{P}_{0}$ and WVR with different street canyon aspect ratio variations. (a) Aspect ratio is $0.4-2.8 ;(\mathbf{b})$ aspect ratio is $0.4 ;(\mathbf{c})$ aspect ratio is $1.0 ;(\mathbf{d})$ aspect ratio is $1.6 ;(\mathbf{e})$ aspect ratio is $2.2 ;(\mathbf{f})$ aspect ratio is 2.8 .

\subsection{Discussion}

The experimental results show that the correlations between the six urban spatial morphology indicators $\left(\mathrm{SVF}, \lambda_{\mathrm{P}}, \lambda_{\mathrm{F}}, \mathrm{P}_{0}, \mathrm{R}_{\alpha}\right.$, and $\mathrm{S}_{\theta}$ ) and WVR at the pedestrian height were very low with the complex and changeable realistic block morphology. This indicates that the above indicators perform well in some simulation studies, specifically under extremely special conditions (i.e., a specific block type with an ideal block morphology). These indicators cannot be effectively applied to actual urban design and planning management until the most applicable block morphology types and value ranges of each indicator have been elucidated in detail.

Through theoretical prediction and practical verification, $\lambda_{P}$ and $\lambda_{F}$ were found to not be suitable for blocks with large height differences, while $\mathrm{P}_{0}$ was not applicable to shallow canyons. The significance of this finding is that the main factor affecting the effectiveness of the above indicators may not be differences in building shapes (i.e., pointtype, slab-type, enclosed-type, etc.) and construction intensity (i.e., floor area ratio, building density, etc.), which have been paid more attention in past classification discussions. The calculation formulae of some of the derived indicators are not affected by these factors in their physical meanings. Therefore, this indicates that the classification method for urban spatial morphology that the architectural perspective takes for granted may lead to deviation from problem in question.

Within the range of this measurement, the correlation coefficient between $\lambda_{\mathrm{F}}$ and WVR was significantly improved here from -0.2395 to -0.7100 by excluding samples with height differences and by excluding shallow street canyon samples, where the correlation coefficient between $P_{0}$ and WVR was significantly improved from 0.4373 to 0.9138 . In the case of deep street canyons, this indicates that $\mathrm{P}_{0}$ can be used as an important control indicator to guide the design of the block wind environment, and if the environment is a shallow canyon and the buildings do not have significant height differences, $\lambda_{\mathrm{F}}$ can be used as a supplementary indicator. 
CFD analysis with a three-dimensional $\mathrm{k}-\varepsilon$ turbulence model was used to solve the RANS equations. This method was used to investigate the influence of the building height difference and street canyon depth on $\lambda_{\mathrm{F}}$ and $\mathrm{P}_{0}$ with the typical building layouts. The results of the CFD simulation and correlation analysis show that when the standard deviation of the building height is less than $15 \mathrm{~m}, \lambda_{\mathrm{F}}$ has a strong correlation with WVR $(|\mathrm{r}|>0.8)$; when the standard deviation is greater than $20 \mathrm{~m}, \lambda_{\mathrm{F}}$ starts to become inaccurate. When the aspect ratio is greater than $2.2, \mathrm{P}_{0}$ has a strong correlation with WVR $(|\mathrm{r}|>0.8)$; when the aspect ratio is less than $1.6, \mathrm{P}_{0}$ starts to become inaccurate. These changes may be caused by the defects of the index formulae themselves. The calculation formula of $\lambda_{\mathrm{F}}$ cannot reflect the random change of the urban canopy height, so it is difficult to accurately reflect the resulting impact on the wind environment. In addition, the principle of $\mathrm{P}_{0}$ is to change the urban canopy topology into a rigid porous medium, which means that the wind environment above the urban canopy and that within it need to be discussed separately. Therefore, compared to the deep street canyons, shallow canyons more likely lead to the inaccurate prediction of $\mathrm{P}_{0}$ as they may contain a greater amount of complicated air exchanges between the wind environment inside and above the urban canopy, while deep street canyons may be less affected.

\section{Conclusions}

For urban design and planning, the rational use of spatial morphology indicators is of great significance for characterizing block wind environments; however, within the complex and changeable reality of the block morphologies, the accuracies of these indicators will be biased. The innovative contribution of this paper is providing two theoretical predictions based on the physical meaning and formulation principles of urban spatial morphology indicators. Specifically, (1) urban spatial morphology indicators based on geometrical city model theory will be affected by building height differences in blocks, and (2) urban spatial morphology indicators based on topological city model theory will be affected by the depths of the street canyons in blocks. In this work, wind environment measurement and CFD simulation were used to verify and quantify the hypotheses. The conclusions of this paper can be summarized as follows:

- Within the complex and changeable reality of block morphologies, the six spatial morphology indicators (SVF, $\lambda_{\mathrm{P}}, \lambda_{\mathrm{F}}, \mathrm{P}_{0}, \mathrm{R}_{\alpha}$, and $\mathrm{S}_{\theta}$ ), which are the current research hotspots for block morphology and block ventilation, have very low correlation with WVR. Although $S_{\theta}$ and $P_{0}$ present a weak correlation, the other indicators all have no correlation with WVR; however, the building height difference and street canyon depth are the main factors that could affect the correlation of $\lambda_{F}$ and $P_{0}$ with the WVR.

- $\quad$ By excluding the measurement samples with height differences, the correlation coefficient between $\lambda_{F}$ and WVR was significantly improved $(|r|=0.7100)$, while by excluding the measurement samples with shallow street canyons, the correlation coefficient between $P_{0}$ and WVR was significantly improved $(|\mathrm{r}|=0.9138)$. The results show that in the case of deep street canyons, $\mathrm{P}_{0}$ can be used as an important control indicator to guide the design of a block wind environment. If the environment features a shallow canyon or the buildings do not feature significant height differences, $\lambda_{\mathrm{F}}$ can be used as a supplementary indicator.

- According to CFD simulation and correlation analysis, $\lambda_{\mathrm{F}}$ and $\mathrm{P}_{0}$ gradually become inaccurate when the standard deviation of building height in a block increases and the aspect ratio decreases, respectively. When the standard deviation of the building height in a block is less than $15 \mathrm{~m}, \lambda_{\mathrm{F}}$ can accurately predict the pedestrian-level wind environment. When the aspect ratio of a block is greater than $2.2, \mathrm{P}_{0}$ can accurately predict the pedestrian-level wind environment; however, when the standard deviation is greater than $20 \mathrm{~m}, \lambda_{\mathrm{F}}$ begins to lose accuracy. When the aspect ratio is less than 1.6, $\mathrm{P}_{0}$ begins to lose accuracy. In high density urban areas where the ventilation urgently requires improvement, $\mathrm{P}_{0}$ and $\lambda_{\mathrm{F}}$ are basically within appropriate value ranges. 
There is no denying that other factors will also influence the effectiveness of the indicators mentioned here. More extensive screening will continue to improve the correlation; however, as the other factors are not the main influencing factors, the space for improvement is limited and the resulting large number of working condition settings will lead to research difficulties.

Author Contributions: Conceptualization, D.W. and X.H.; Data curation, D.W.; Formal analysis, D.W.; Funding acquisition, B.L. and H.C.; Investigation, D.W. and X.H.; Methodology, D.W. and Y.C.; Project administration, B.L. and H.C.; Resources, B.L. and H.C.; Software, D.W. and Y.C.; Supervision, X.H.; Validation, X.H.; Visualization, D.W.; Writing—original draft, D.W.; Writing-review \& editing, D.W. and X.H. All authors have read and agreed to the published version of the manuscript.

Funding: This paper was supported by projects of the National Natural Science Foundation of China Project (No. 51538004) (No. 51778251) (No. 52078229), and the Fundamental Research Funds for the Central Universities, HUST (No. 2019kfyXKJC030).

Data Availability Statement: The data applied in this study are available on request from the first and the corresponding author.

Conflicts of Interest: The authors declare no conflict of interest.

\section{References}

1. Lettau, H. Note on Aerodynamic Roughness-Parameter Estimation on the Basis of Roughness-Element Description. J. Appl. Meteorol. 1969, 8, 828-832. [CrossRef]

2. Pasquill, F. Prediction of Diffusion Over an Urban Area, Current Practice and Future Prospects. In Proceedings of Symposium on Multiple-Source Urban Diffusion Models; US Environmental Protection Agency: Washington, DC, USA, 1970.

3. Shaw, R.H.; Pereira, A.R. Aerodynamic roughness of a plant canopy: A numerical experiment. Agric. Meteorol. 1982, 26, 51-65. [CrossRef]

4. Kondo, J.; Yamazawa, H. Aerodynamic roughness over an inhomogeneous ground surface. Bound.-Layer Meteorol. 1986, 35, 331-348. [CrossRef]

5. Rafailidis, S. Influence of Building Areal Density and Roof Shape on the Wind Characteristics Above a Town. Bound.-Layer Meteorol. 1997, 85, 255-271. [CrossRef]

6. Ratti, C.; Richens, P. Urban Texture Analysis with Image Processing Techniques. Comput. Build. 1969, 8, 828-832.

7. Adolphe, L. A Simplified Model of Urban Morphology: Application to an Analysis of the Environmental Performance of Cities. Environ. Plan. B Plan. Des. 2001, 28, 183-200. [CrossRef]

8. Adolphe, L. Modelling the Link between Built Environment and Urban Climate: Towards Simplified Indicators of the City Environment. In Proceedings of the Seventh International IBPSA Conference, Rio de Janeiro, Brazil, 13-15 August 2001.

9. Zhang, T. Study on Coupling of Wind Environment and Spatial Form in Urban Center; Southeast University: Nanjing, China, 2015.

10. Hicks, B.B.; Hosker, R.P.; Womack, J.D. Comparisons of Wet and Dry Deposition: The First Year of Trial Dry Deposition Monitoring; Presented at the The Chemistry of Acid Rain: Sources of Atmospheric Processes; ACS Publications: Washington, DC, USA, 1987.

11. Oke, T.R. Street Design and Urban Canopy LayerClimate. Energy Build. 1988, 103-113. [CrossRef]

12. Theurer, W. Dispersion of ground-level emissions in complex built-up areas. J. Wind Eng. Ind. Aerodyn. 1993, 44, $2721-2732$.

13. Santiago, J.L.; Martilli, A. A Dynamic Urban Canopy Parameterization for Mesoscale Models Based on Computational Fluid Dynamics Reynolds-Averaged Navier-Stokes Microscale Simulations. Bound.-Layer Meteorol. 2010, 137, 417-439. [CrossRef]

14. Ng, E.; Yuan, C.; Chen, L.; Ren, C.; Fung, J.C.H. Improving the wind environment in high-density cities by understanding urban morphology and surface roughness: A study in Hong Kong. Landsc. Urban. Plan. 2011, 101, 59-74. [CrossRef]

15. Yuan, S. Quantitative Analysis on Street Network in Urban Environment; Tianjin University: Tianjin, China, 2011.

16. China's Ministry of Housing and Urban-Rural Development, MOHURD. Design Standard for Thermal Environment in Urban Residential Areas; MOHURD: Beijing, China, 2013.

17. Zhou, Y. Exploration on 'Build-To-Line Ratio' in Urban Planning Control on Street Interface. City Plan. Rev. 2016, 40, 25-29.

18. Zhang, S.Y.; Chen, Y. Degree of enclosure as outdoor space form parameter study based on the urban microclimate analysis: A case study on office building site design in Shanghai. J. East. China Norm. Univ. 2016, 06, 1-26.

19. Oke, T.R. City Size and the Urban Heat Island. Atmospheric Environ. Pergamon Press 1973, 7, 769-779. [CrossRef]

20. Steyn, D.G. The calculation of view factors from fisheye-lens photographs: Research note. Atmos.-Ocean. 1980, 18, 254-258. [CrossRef]

21. Voogt, J.A.; Oke, T.R. Complete Urban Surface Temperatures. J. Appl. Meteorol. 1997, 36, 16. [CrossRef]

22. Kanda, M.; Kawai, T.; Nakagawa, K. A Simple Theoretical Radiation Scheme for Regular Building Arrays. Layer Meteorol. 2005, 114, 71-90. [CrossRef]

23. Kanda, M.; Kawai, T.; Kanega, M.; Moriwaki, R.; Narita, K.; Hagishima, A. A Simple Energy Balance Model for Regular Building Arrays. Bound.-Layer Meteorol. 2005, 116, 423-443. [CrossRef] 
24. Kondo, H.; Genchi, Y.; Kikegawa, Y.; Ohashi, Y.; Yoshikado, H.; Komiyama, H. Development of a Multi-Layer Urban Canopy Model for the Analysis of Energy Consumption in a Big City: Structure of the Urban Canopy Model and its Basic Performance. Bound.-Layer Meteorol. 2005, 116, 395-421. [CrossRef]

25. Shashua-Bar, L.; Hoffman, M.E.; Tzamir, Y. Integrated thermal effects of generic built forms and vegetation on the UCL microclimate. Build. Environ. 2006, 41, 343-354. [CrossRef]

26. Wen, X. Study on Block Space form Design Strategy Research Based on Optimization of Natural Ventilation in Wuhan; Huazhong University of Science and Technology: Wuhan, China, 2012.

27. Deshun, Z.; Zhen, W. Influence of Vault Sector on Summer Square Microclimate and Human Thermal Comfort. Landsc. Archit. 2018, 25, 27-31.

28. Xing, H.; Di, W.; Baofeng, L.; Hong, C. Research on the correlation between urban spatial morphology indicators and block wind environment. New Architecture 2020, 5, 139-143.

29. Johnson, G.T.; Oke, T.R.; Lyons, T.J.; Steyn, D.G.; Watson, I.D.; Voogt, J.A. Simulation of surface urban heat islands under 'IDEAL'conditions at night part 1: Theory and tests against field data. Bound.-Layer Meteorol. 1991, 56, 275-294. [CrossRef]

30. Mills, G.M. Simulation of the energy budget of an urban canyon-I. Model structure and sensitivity test. Atmos. Environ. Part B Urban. Atmos. 1993, 27, 157-170. [CrossRef]

31. Arnfield, J.; Herbert, J.M.; Johnson, G.T. A numerical simulation investigation of urban canyon energy budget variations. In Proceedings of the 2nd AMS Urban environment Symposium, Albuquerque, New Mexico, 2-7 November 1998; pp. 2-5.

32. Martilli, A. On the Derivation of Input Parameters for Urban Canopy Models from Urban Morphological Datasets. Bound.-Layer Meteorol. 2009, 130, 301-306. [CrossRef]

33. Martilli, A.; Clappier, A.; Rotach, M.W. An Urban Surface Exchange Parameterisation for Mesoscale Models. Bound.-Layer Meteorol. 2002, 104, 261-304. [CrossRef]

34. Cornelis, Z.; Kosten, C.W. Sound Absorbing Materials; Elsevier Publishing Company: New York, NY, USA, 1949.

35. $\mathrm{Ng}$, E. Policies and technical guidelines for urban planning of high-density cities-Air ventilation assessment (AVA) of Hong Kong. Build. Environ. 2009, 44, 1478-1488. [CrossRef] [PubMed]

36. Tominaga, Y.; Stathopoulos, T. CFD simulation of near-field pollutant dispersion in the urban environment: A review of current modeling techniques. Atmos. Environ. 2013, 79, 716-730. [CrossRef]

37. Blocken, B.; Stathopoulos, T.; Saathoff, P.; Wang, X. Numerical evaluation of pollutant dispersion in the built environment: Comparisons between models and experiments. J. Wind Eng. Ind. Aerodyn. 2008, 96, 1817-1831. [CrossRef]

38. Toparlara, Y.; Blockena, B.; Vos, P.; van Heijst, G.J.F.; Janssen, W.D.; van Hooff, T.; Montazeri, H.; Timmermans, H.J.P. CFD simulation and validation of urban microclimate: A case study for Bergpolder Zuid, Rotterdam. Build. Environ. 2015, 83, 79-90. [CrossRef]

39. Tominaga, Y.; Mochida, A.; Murakami, S.; Sawaki, S. Comparison of various revised k-e models and LES applied to flow around a high-rise building model with 1:1:2 shape placed within the surface boundary layer. J. Wind Eng. Ind. Aerodyn. 2008, 96, 23. [CrossRef]

40. Richards, P.J.; Hoxey, R.P. Appropriate boundary conditions for computational wind engineering models using the k-E turbulence model. J. Wind Eng. Ind. Aerodyn. 1993, 46, 145-153. [CrossRef]

41. Cheng, Y.; Lien, F.S.; Yee, E.; Sinclair, R. A comparison of large Eddy simulations with a standard k- $\varepsilon$ Reynolds-averaged Navier-Stokes model for the prediction of a fully developed turbulent flow over a matrix of cubes. J. Wind Eng. Ind. Aerodyn. 2003, 91, 1301-1328. [CrossRef]

42. Bady, M.; Kato, S.; Huang, H. Towards the application of indoor ventilation efficiency indices to evaluate the air quality of urban areas. Build. Environ. 2008, 43, 1991-2004. [CrossRef]

43. Peng, Y.; Gao, Z.; Buccolieri, R.; Ding, W. An Investigation of the Quantitative Correlation between Urban Morphology Parameters and Outdoor Ventilation Efficiency Indices. Atmosphere 2019, 10, 33. [CrossRef]

44. Hang, J.; Li, Y.; Sandberg, M.; Buccolieri, R.; di Sabati, S. The influence of building height variability on pollutant dispersion and pedestrian ventilation in idealized high-rise urban areas. Build. Environ. 2012, 56, 346-360. [CrossRef]

45. Hang, J.; Li, Y.; Sandberg, M.; Claesson, L. Wind conditions and ventilation in high-rise long street models. Build. Environ. 2010, 45, 1353-1365. [CrossRef]

46. Hang, J.; Sandberg, M.; Li, Y. Effect of urban morphology on wind condition in idealized city models. Atmos. Environ. 2009, 43, 869-878. [CrossRef]

47. Makvandi, M.; Li, B.; Elsadek, M.; Khodabakhshi, Z.; Ahmadi, M. The Interactive Impact of Building Diversity on the Thermal Balance and Micro-Climate Change under the Influence of Rapid Urbanization. Sustainability 2019, 11, 1662. [CrossRef]

48. Houda, S.; Belarbi, R.; Zemmouri, N. A CFD Comsol model for simulating complex urban flow. Energy Procedia 2017, 139, 373-378. [CrossRef]

49. Song, J. The Improvement of Ventilation Design in School Buildings Using CFD Simulation. Procedia Eng. 2015, 121, 7. [CrossRef]

50. Mei, S.; Chang, J.; Hu, J.; Zhang, J.; Tian, L.; Zhao, F. Numerical Simulation of Urban Ventilation with Different Building Scales. In Proceedings of the 2014 ISFMFE—6th International Symposium on Fluid Machinery and Fluid Engineering, Wuhan, China, 22-25 October 2014. 
51. Franke, J.; Hellsten, A.; Schlünzen, H.; Carissimo, B. Best Practice Guideline for The CFD Simulation of Flows in the Urban Environment: COST Action 732 Quality Assurance and Improvement of Microscale Meteorological Models; Meteorological Inst: Hamburg, Germany, 2007.

52. Moonen, P.; Dorer, V.; Carmeliet, J. Effect of flow unsteadiness on the mean wind flow pattern in an idealized urban environment. J. Wind Eng. Ind. Aerodyn. 2012, 104-106, 389-396. [CrossRef]

53. Franke, J.; Hirsch, C.; Jensen, A.G.; Krüs, H.W.; Schatzmann, M.; Westbury, P.S.; Miles, S.D.; Wisse, J.A.; Wright, N.G. Recommendations on the use of CFD in wind engineering. COST Action C14, Impact of Wind and Storm on City Life Built Environment. In Proceedings of the International Conference on Urban Wind Engineering and Building Aerodynamics, Sint-Genesius-Rode, Belgium, 5-7 May 2004.

54. Celik, I.B.; Ghia, U.; Roache, P.J.; Freitas, C.J.; Raad, H.C.E. Procedure for Estimation and Reporting of Uncertainty Due to Discretization in CFD Applications. J. Fluids Eng. 2008, 7, 078001. [CrossRef]

55. Zhang, N.; Du, Y.; Miao, S. A microscale model for air pollutant dispersion simulation in urban areas: Presentation of the model and performance over a single building. Adv. Atmos. Sci. 2016, 33, 184-192. [CrossRef]

56. Di Sabatino, S.; Solazzo, E.; Paradisi, P.; Britter, R. A Simple Model for Spatially-averaged Wind Profiles Within and Above an Urban Canopy. Bound.-Layer Meteorol. 2008, 127, 131-151. [CrossRef]

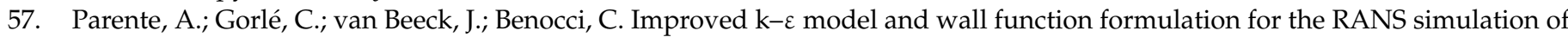
ABL flows. J. Wind Eng. Ind. Aerodyn. 2011, 99, 267-278. [CrossRef]

58. Vardoulakis, S.; Dimitrova, R.; Richards, K.; Hamlyn, D.; Camilleri, G.; Weeks, M.; Sini, J.; Britter, R.; Borrego, C.; Schatzmann, M.; et al. Numerical Model Inter-comparison for Wind Flow and Turbulence Around Single-Block Buildings. Environ. Model. Assess. 2011, 16, 169-181. [CrossRef] 